\title{
From dinosaurs to birds: a tail of evolution
}

\author{
Dana J Rashid ${ }^{1 *}$, Susan C Chapman², Hans CE Larsson ${ }^{3}$, Chris L Organ ${ }^{1,4}$, Anne-Gaelle Bebin ${ }^{1,5}$, Christa S Merzdorf ${ }^{6}$, \\ Roger Bradley ${ }^{6}$ and John R Horner ${ }^{1}$
}

\begin{abstract}
A particularly critical event in avian evolution was the transition from long- to short-tailed birds. Primitive bird tails underwent significant alteration, most notably reduction of the number of caudal vertebrae and fusion of the distal caudal vertebrae into an ossified pygostyle. These changes, among others, occurred over a very short evolutionary interval, which brings into focus the underlying mechanisms behind those changes. Despite the wealth of studies delving into avian evolution, virtually nothing is understood about the genetic and developmental events responsible for the emergence of short, fused tails. In this review, we summarize the current understanding of the signaling pathways and morphological events that contribute to tail extension and termination and examine how mutations affecting the genes that control these pathways might influence the evolution of the avian tail. To generate a list of candidate genes that may have been modulated in the transition to short-tailed birds, we analyzed a comprehensive set of mouse mutants. Interestingly, a prevalent pleiotropic effect of mutations that cause fused caudal vertebral bodies (as in the pygostyles of birds) is tail truncation. We identified 23 mutations in this class, and these were primarily restricted to genes involved in axial extension. At least half of the mutations that cause short, fused tails lie in the Notch/Wnt pathway of somite boundary formation or differentiation, leading to changes in somite number or size. Several of the mutations also cause additional bone fusions in the trunk skeleton, reminiscent of those observed in primitive and modern birds. All of our findings were correlated to the fossil record. An open question is whether the relatively sudden appearance of short-tailed birds in the fossil record could be accounted for, at least in part, by the pleiotropic effects generated by a relatively small number of mutational events.
\end{abstract}

Keywords: Archaeopteryx, Avian, Bird evolution, Confuciusornis, Dinosaur, Jeholornis, Sapeornis, Somitogenesis, Tail

\section{Review}

\section{Introduction}

Tails of extant birds are an evolutionary novelty. They are critical for powered flight, ensure reproductive success by attracting mates, and safeguard relatives by communicating warning signals. Extant bird tails consist proximally of a small series of unfused caudal vertebrae with a high range of motion. These articulate to a distal rod-like pygostyle, composed of several fused caudal vertebrae, which supports the retricial bulb and associated muscles and feathers for controlling tail fan and contour shape. This specialized tail is present throughout the entire diversity of living birds, albeit with many modifications for clade-specific behaviors. A well-sampled fossil record documents the evolutionary

\footnotetext{
*Correspondence: danarashid5@gmail.com

${ }^{1}$ Museum of the Rockies, Montana State University, 600 West Kagy Blvd, Bozeman, MT 59717, USA

Full list of author information is available at the end of the article
}

transformation from the ancestral long 'reptilian' tail to the short, distally fused tail $[1,2]$. Yet, the specific developmental mechanisms that facilitated this dramatic anatomical change are unknown. This gap in knowledge constitutes a rich vein for future research, one that would benefit from our current understanding of axial developmental mechanisms.

The phenotypic changes that arose in the transition from ancestral long-tailed to short-tailed birds were manifested from changes during embryonic development, indicating that the study of mutations in embryonic models is essential to elucidating the mechanism of tail shortening. Mutations in key developmental genes and/or their regulation can cause multiple changes in morphology. Indeed, pleiotropic effects are observed in the vertebrate axial skeleton for a number of mutations [3]. Given the multiple phenotypes that can arise with single mutations, can the perceived sudden appearance 
of short-tailed birds be due to a lack of intermediate specimens in the fossil record, or from a very limited number of mutations that caused significant alterations to the primitive bird skeleton in a relatively short period of time? With reference to the fossil record, we first review the evolutionary history and early skeletal development of the bird tail, and discuss the developmental mechanisms involved in axial extension and termination. We then present a comprehensive survey of mouse tail mutants with the purpose of examining conserved patterns of mutation and likely candidates within the tail gene regulatory network that may have played major roles in reducing the bird tail. These paleontological, genetic, and developmental analyses are applied to the critical juncture in bird evolution at which tails were truncated and flight was greatly enhanced, in the late Jurassic to Early Cretaceous transition of primitive longtailed to short-tailed birds.

\section{Background}

The origin of the derived bird tail occurred over a remarkably short evolutionary interval, as evidenced by the short-lived co-occurrence of both long- and shorttailed birds in equivalent spatio-temporal fossil formations (Figure 1). Nearly all non-avian theropod dinosaurs sported long, 'reptilian' tails. These taxa were bipedal, so the tail likely had a counterbalance function. It also had robust transverse processes on the proximal caudal vertebrae that would have served as attachment sites for the large caudofemoralis muscles that were the primary hind limb retractors [4]. The oldest known bird, Archaeopteryx, dated to 150 million years ago, defines the clade Aves [5-7] or Avialae [8]. Its fully formed flight feathers, elongated wings, and evidence of capable powered flight, all ally Archaeopteryx with birds $[9,10]$. Yet, the presence of teeth, clawed and unfused fingers, and an elongated, bony tail are characteristics shared with non-avian theropod dinosaurs. Paravians, including Archaeopteryx, are characterized by long tails $[11,12]$, some fusion of synsacral vertebrae, and varying flight capability (Figure 1). Most deinonychosaurians had between 20 and 30 caudal vertebrae. Oviraptorosaurs, probably the immediate outgroup to Paraves, had relatively shorter tails. These shorter tails were due not just to a modest decrease in the number of caudal vertebrae relative to other non-avian theropods, but more generally to a reduction in individual lengths of the more distal caudals [13]. Interestingly, several oviraptorosaurs have been documented to have the distal caudal vertebrae co-ossified into a pygostyle-like structure that braced a fan-like arrangement of retrices [13-16]. Another more prominent independent reduction of tail length occurred in Epidexipteryx, a Mid- or Late-Jurassic maniraptoran dinosaur [17]. Its tail had only 16 caudal vertebrae with the distal ten tightly articulated to form a stiffened rod supporting four unique, ribbon-like, tail feathers.

A marked decrease in the number of caudal vertebrae becomes very evident in the bird lineage from the Avialae subgroup of maniraptoran dinosaurs onward (Figure 2). Archaeopteryx retained an ancestral caudal vertebral count of between 20 and 23 [18]. The next most basal bird, Jeholornis, from the Jiufotang Formation of China and dated at approximately 120 million years old [19], was also long-tailed, and had 22 caudal vertebrae that are nearly identical to those of Archaeopteryx [12]. The same formation preserves the next most basal bird, Sapeornis $[20,21]$. This taxon is the first bird to express a shortened tail with only six to seven free caudal vertebrae and an elongated pygostyle. All taxa derived from the last common ancestor of Sapeornis and extant birds retain a reduced tail ending in a pygostyle, suggesting that this evolutionary transformation is highly adaptive and necessary for bird physiology. A single specimen, Zhongornis, may potentially lie phylogenetically between the longtailed and short-tailed birds. Zhongornis is known from a single specimen representing a juvenile that was either fledged or near fledgling [22]. The juvenile nature of this taxon makes any phylogenetic placement uncertain, but it does have a unique tail morphology that may be either a phylogenetic or ontogenetic signal. Its tail consisted of 13 caudal vertebrae, with the last four partially fused and forming what may be a partial pygostyle.

Despite these variations, there is consensus that shorttailed primitive birds appear in the fossil record relatively suddenly, with fewer caudal vertebrae terminating in a fused distal pygostyle, with abrupt rather than gradual loss of tails [2]. These short-tailed birds, the confuciusornithids, enantiornithines and early ornithurines, had acquired a number of other more modern bird-like traits that differed from their long-tailed primitive bird predecessors. These traits included more extensive synsacral, sternum, and digit fusion (Figure 1), as well as uncinate processes fused to adjacent ribs [23,24]. Osteological modifications were coupled to changes in musculature and behavior. With tail truncation and multiple bone fusions came advances in flight mechanics. Some of those flight advances can be attributed to the pygostyle, partly through its contributions to tail feather control [25]. Because Jeholornis had a long tail with a proximal feather fan, there is some debate about whether the pygostyle co-evolved with mobile fan-shaped feather arrays [26]. Whatever their origin, the pygostyle-associated feather fans differed from the frond-type arrays of more primitive long-tailed ancestors [25]. Fan-shaped feather arrays play significant roles in sexual selection in modern birds, and likely played analogous functions in their more primitive short-tailed ancestors (Figure 3) [27]. 


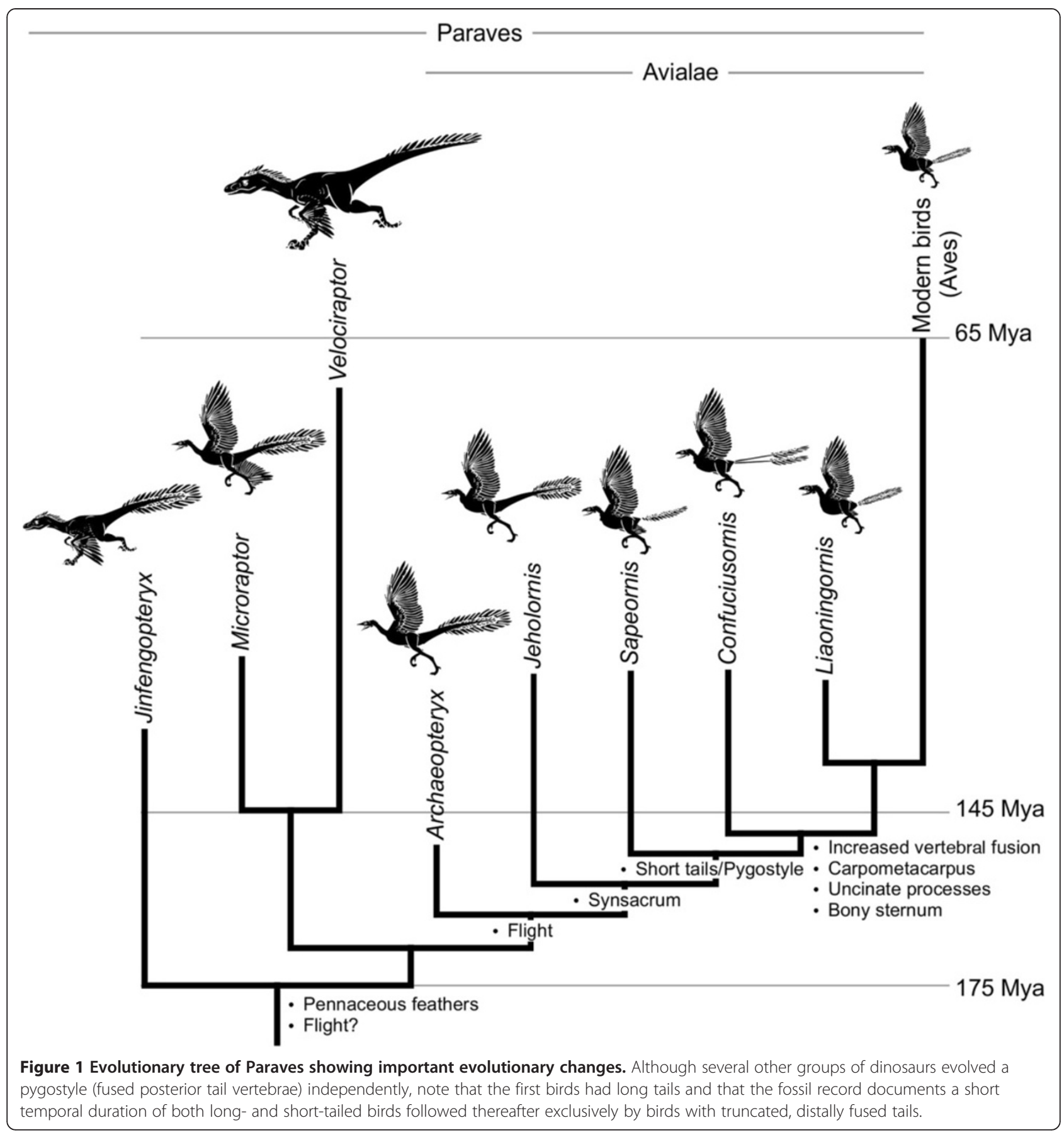

Truncation of the bird tail was also concurrent with reduction and shortening of the large caudofemoralis muscle (CML). Reduction of this muscle is not exclusive to birds and is evident among all maniraptoran subgroups, as hypothesized from the lack of a clearly distinguishable fourth trochanter, the CML insertion site. More profound CML reductions, however, are predicted in early birds with truncated tails [4]. In theropods and in modern reptiles, the CML originates on the proximal caudal vertebrae, with attachment points on the ventral transverse processes and hemal arches (chevrons). In modern birds, the CML is absent or reduced, and where present, its origination site is on the pygostyle [4]. One exception is the rumpless Araucana chicken; in this case, the CML originates on the pelvis [28]. It is interesting to note that in Sapeornis, the most basal short-tailed bird, the caudal vertebrae retained hemal arches [21], but the Confuciusornis tail was more derived, and no hemal arches are observed [29] (Figure 2). The presence of hemal arches in Sapeornis indicate its CML was more substantial than in 

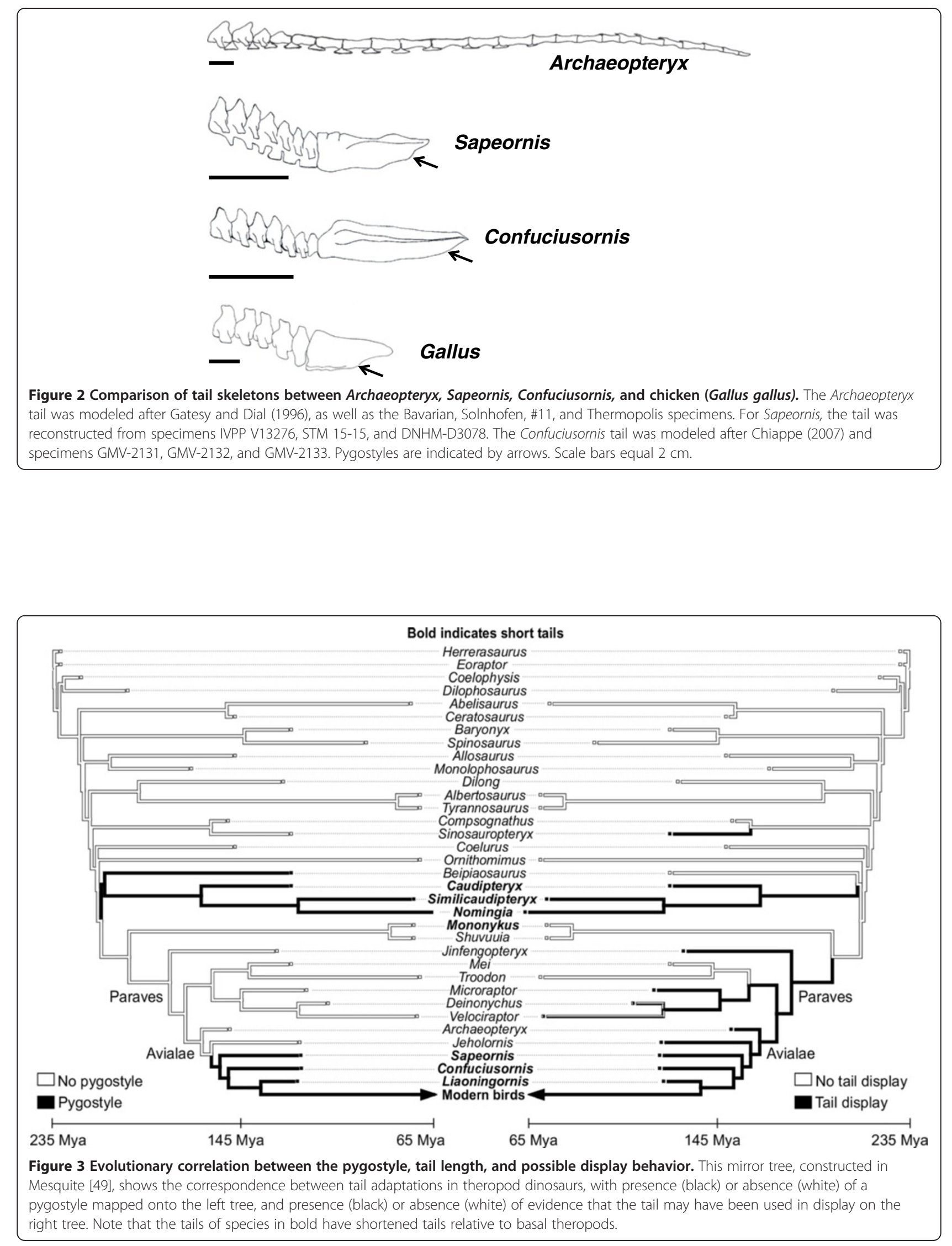
Confuciusornis, suggesting that formation of the pygostyle alone is not sufficient to cause the degree of CML reduction seen in Confuciusornis and in modern birds.

CML modifications, and others within the tail, may have facilitated the abrupt transition to short-tailed birds due to function decoupling. Decoupling of locomotor structures from each other is a hallmark of the origin of birds and powered flight and was most focused in the forelimb and tail [30,31]. The tail of extant birds, for example, functions to provide lift, braking, and turning surfaces for controlled flight [32-36], but is decoupled from the hind limb and has lost its ancestral contributions to terrestrial (as opposed to aerial) locomotion. Therefore, the complex functional repertoire of extant bird tails is achieved by a primary decoupling of the tail from the hind limbs followed by additional flight adaptations within the tail.

\section{Tail development}

\section{Tail structures}

The mechanisms directing tail growth are similar among vertebrates, and have been evolutionarily conserved since before the dinosaurs. Vertebrate embryo tails are constructed of the same basic elements, arranged in the same basic pattern (Figure 4). Along the dorsal midline lies the neural tube, which gives rise to the brain and spinal cord. Ventral to the floor plate of the neural tube is the notochord, a structure that is the precursor to the nucleus pulposus in spinal discs [37], and is necessary for proper formation of the neural tube and somites [38-40]. Ventral to the notochord in the posterior part of the embryo is the hindgut, the most caudal part of which is known as the tailgut. Somites, discrete paired segments of paraxial mesoderm, flank the neural tube and are the developmental precursors of the axial vertebrae, skeletal muscle and dermis. In addition, neural crest cells, integral to early development, overlay the dorsal neural tube and subsequently migrate ventrally to form the majority of the peripheral nervous system, including the sensory ganglia of the tail [41]. A pool of undifferentiated progenitor mesenchyme cells in the tail bud, the chordoneural hinge $(\mathrm{CNH})$, is the primary source of cells from which tail elongation proceeds $[42,43]$. Located ventral to the tail tip and adjacent to the forming tailgut is the ventral ectodermal ridge (VER), the remnant of Hensen's node, through which the final gastrulating cells migrate [44-46].

\section{Axial extension}

Early in vertebrate embryo development a body plan is established, whereby somites are added sequentially along the axis. Somitogenesis has been recently reviewed elsewhere $[47,48]$, but in brief, begins with the formation of the presomitic mesoderm (PSM) during gastrulation [49]. Following gastrulation, the region of PSM where somite pairs form is established, at least in part, by the intersection of two opposing extracellular gradients: the Wnt/Fgf gradient and the retinoic acid (RA) gradient. Wnt and Fgf proteins are secreted from the posterior of the embryo, whereas the RA gradient arises from the most recently formed somites. These soluble factors interact at a critical threshold, termed the determination front, where new somite formation is initiated (Figure 5) [50-55]. The addition of somite pairs is controlled by an oscillating 'segmentation clock' signaling cascade, which repeats for each somite pair. The mechanisms guiding the oscillating clock are not completely understood; however, a number of clock participants and their roles have been described [52,56-60]. Among clock genes with time-dependent oscillating expression patterns are members of the Wnt, Fgf, and Notch pathways. The cooperative action of the molecular pathways functions to synchronize the oscillation of the clock, such that a wave front of clock-gene expression moves anterior to posterior along the embryonic axis. Negative feedback regulation of clock genes by their targets within activated cells as well as RNA instability are mechanisms employed to generate oscillating gene expression [61-63]. The boundaries of newly formed somites are established by positional expression of Notch pathway genes; these genes also establish the anterior/posterior axis of each somite [64-68]. As somites are sequentially added, ingression through the primitive streak and cell division in the PSM and CNH feeds into and maintains the PSM for continued somitogenesis [42]. Krol and colleagues conducted a particularly interesting study comparing the transcriptomes of mouse, chicken and zebrafish during one somite extension. They discovered that despite a high level of conservation of the major pathways and events of somitogenesis, the genes that show oscillating expression can differ. Only two Notch pathway proteins, Her1 and Her5, were shown to oscillate in all three vertebrates, but all other identified oscillating proteins, primarily members of the Fgf, Notch, and Wnt cascades, were specific to each vertebrate. This suggests an unexpected evolutionary plasticity in a critical developmental process. Specifically, members of the Fgf, Notch, and Wnt pathways were likely targets of evolution in axial extension [69].

\section{Regional specification}

The regional identity of the somites, that is, cervical, thoracic, lumbar, sacral or caudal, is determined by Hox gene expression [70]. The Hox genes were first discovered in Drosophila, where Hox gene mutations changed the positional identity of segments along the Drosophila body axis [71]. Drosophila and other non-vertebrates have up to 14 genes contained within one Hox cluster. Due to tandem genomic duplications, vertebrate Hox genes usually appear in four paralogous DNA clusters, A through D. Hox genes within those clusters, numbered 1 


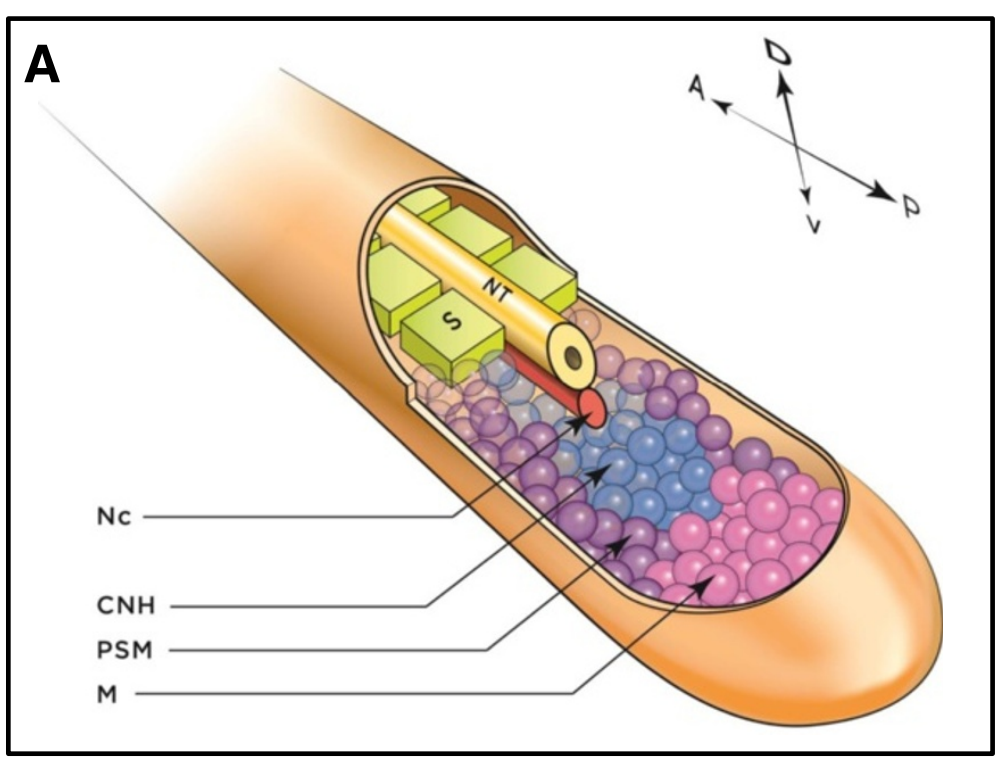

B
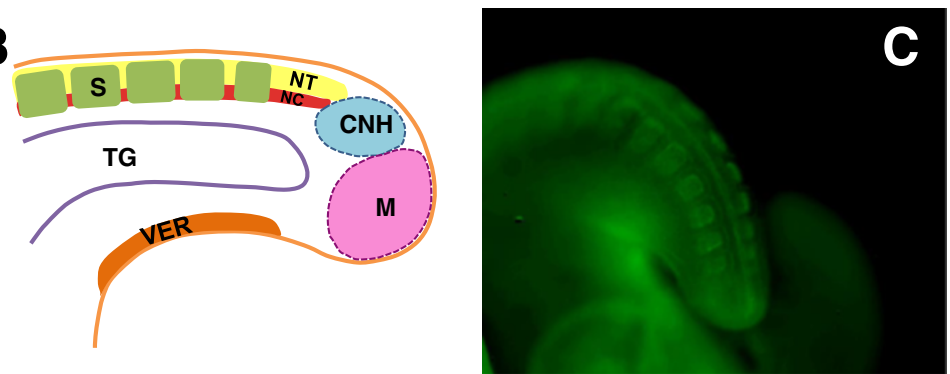

Figure 4 Structures in the embryonic vertebrate tail. (A) Three-dimensional (3-D) reconstruction of an extending vertebrate embryo tail. Axial structures include the NT and Nc; lateral to these are the paraxial somites and PSM. Somites are the embryonic precursors to skeletal muscle, ribs, and bony vertebrae; motor and interneurons are derived from the NT; the CNH is the remnant of Hensen's node and contains pluripotent cells; the PSM is the source of cells from which somites arise; and mesenchyme cells (M) at the distal tip of the tail feed into the CNH. Not shown: neural crest and ventral structures. Axis indicates Anterior, A; Posterior, P; Dorsal, D; and Ventral, V. (B) Lateral schematic of tail structures. The axial NT and Nc and paraxial somites and PSM lie dorsal to the TG, which in turn is dorsal to the VER. The VER is the remnant of the Hensen's node and a source of growth-promoting signals. Not shown: neural crest and PSM. (C) Chick embryo tail stage HH23 stained for somites with FITC-phalloidin. Abbreviations: $\mathrm{CNH}$, chordoneural hinge; $\mathrm{M}$, mesenchyme, Nc, notochord; NT, neural tube; PSM, presomitic mesoderm; S, somite; TG, tailgut; VER, ventral ectodermal ridge.

through 13, are collinearly expressed along the body axis sequentially, with Hox1 most rostral and Hox13 most caudal [72-77]. In any given vertebrate or non-vertebrate organism, not all 13 or 14 Hox genes within each paralogous cluster are present [78]. Teleost fish sustained an additional genome duplication, and therefore, possess another set of Hox clusters. While four more Hox clusters would be expected, three have been identified, bringing the total number of clusters in teleosts to seven [79]. In vertebrates, Hox genes perform analogous body patterning functions to Drosophila and are most evident in defining the rostral to caudal identities of vertebrae. Most Hox genes are thought to specify regional axial identity by initially conferring anteroposterior patterning during gastrulation [80], followed by fine-tuning within maturing mesoderm and neuroectoderm (reviewed in [81]). Mutations in Hox genes typically cause homeotic transformation, in which vertebrae take on characteristics that are more anterior or posterior to their position. Concurrent disruptions in all three mouse Hox10 genes, for example, cause the lumbar vertebrae to transform into thoracic-like vertebrae with ribs [82]. Conversely, loss-of-function of the more posteriorly expressed three Hox11 genes in mice results in a failure to form sacral vertebrae, being replaced by vertebrae with lumbar morphology. While these mutations generally preserve the overall number of vertebral elements, some Hox gene disruptions can increase or (more commonly) decrease total vertebrae numbers (reviewed in [78]).

There are additional factors that contribute to regional specification of the tail. Gdf11, for example, which encodes a Bmp (Bone morphogenetic protein)-related growth factor, acts to establish the trunk-to-tail transition in vertebrates [83]. Also involved in caudal axial patterning and 


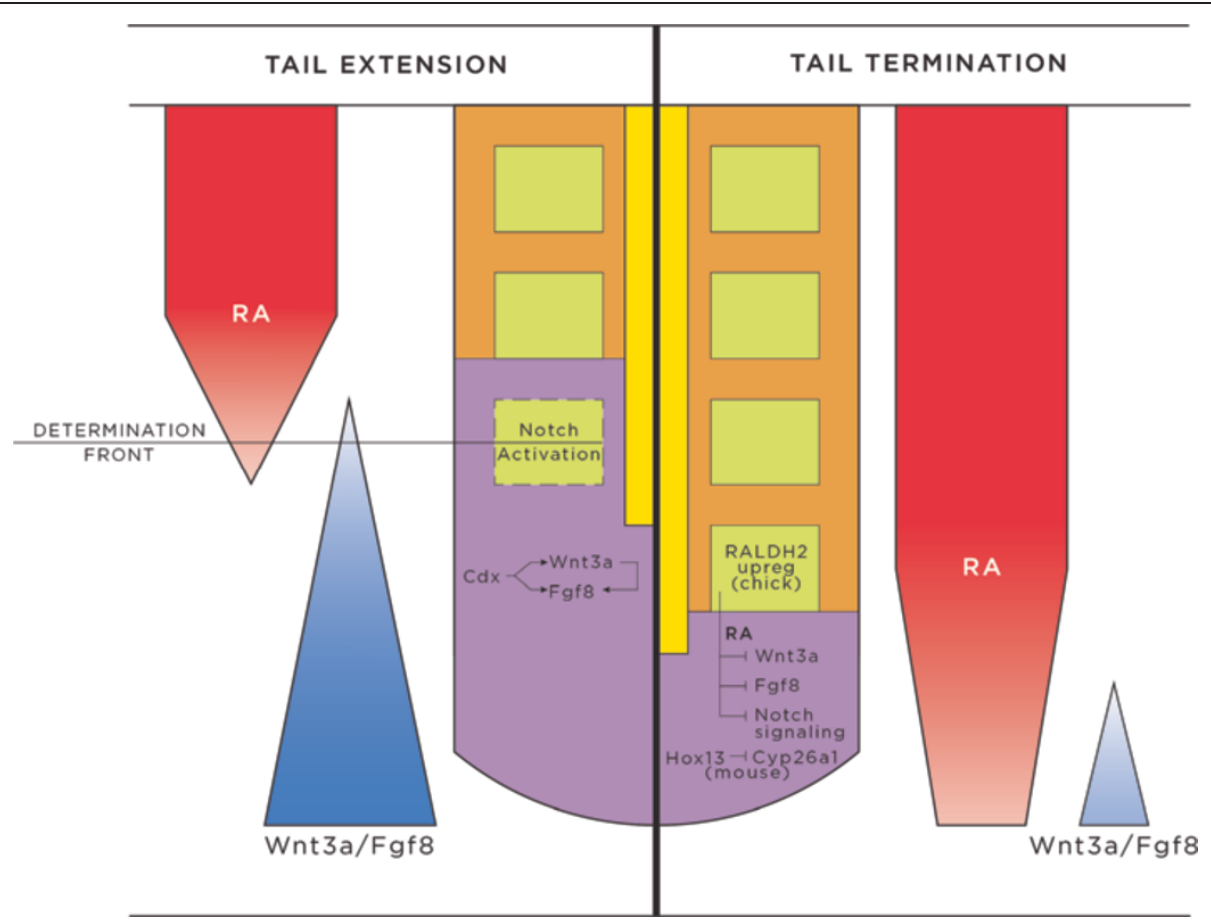

Figure 5 Tail extension and axial termination signaling schematic. During tail extension (depicted on left), somitogenesis is actively proceeding, with new somites forming from PSM at the determination front. Activities from Cdx proteins, Wnts, and Fgfs establish a posterior Wnt3a/Fgf8 gradient, which opposes an anterior RA gradient. These opposing gradients allow the creation of the determination front, and activation of the Notch pathway. Cycling expression patterns of Wnt, Fgf, and Notch pathway genes follow a clock wave-front model, promoting somite induction, segmentation and differentiation in successive waves, to add somites sequentially, rostral to caudal, down the vertebrate axis. During tail termination (right), the RA gradient is unopposed, due to progressively decreasing concentrations of Wnts and Fgfs. Contributions from RA (increased in chick via RALDH2), Hox genes, decreased concentrations of Cyp26a1 (mouse), Wnts and Fgfs, inhibition of the Notch pathway, apoptosis, and loss of cell division and cell recruitment in the $\mathrm{CNH}$ act to terminate the tail. Abbreviations: $\mathrm{CNH}$, chordoneural hinge; RA, retinoic acid.

posterior expansion are the $C d x$ genes, which are expressed primarily in the posterior end of the vertebrate embryo. $C d x$ and Hox genes are related, and are thought to have derived from the same ProtoHox cluster [84]; both have been highly conserved throughout evolution and play roles in body patterning from cnidarians to higher vertebrates. Three separate $C d x$ genes are generally expressed in vertebrates, and if two of these are knocked out in the mouse ( $C d x 2$ and $C d \times 4)$, axis extension is prevented and some trunk and tail structures do not form [85]. Control of $C d x$ and Hox genes is mediated through the Fgf, Notch, RA and Wnt signaling pathways, underlining the crucial contributions of these pathways to extending and shaping the spinal column $[78,86,87]$.

\section{Caudal positional identity}

The correlations between Hox gene expression pattern and vertebral specification are not simple, and functional redundancies are prevalent. In both chick and mouse, the anterior expression boundary of Hoxd12 marks the transition between sacral and caudal vertebrae [88]. Hoxd12 contributes to caudal specification, but its disruption in the mouse causes limb abnormalities [89]. In the mouse, loss-of-function studies have shown that caudal vertebrae are also specified by Hoxb13 [90]. Adding further complexity to the system, Hoxb8 in the mouse is expressed in mesoderm in the tail (and also more anteriorly). Hoxb8 knockout does not alter caudal vertebrae identity [91], but it can rescue tail vertebrae in $C d x 2 / 4$ mouse mutants [81], indicating that it may contribute to caudal somite extension. Further genetic analyses will help to determine whether the functions of these Hox genes in the tail are universal in vertebrates.

\section{Tail termination}

Whether a tail is long, like that of a mouse, or short, as in a chicken, a number of converging developmental events ensure that the tail stops elongating at a characteristic point in each species and does not grow indefinitely. At the termination of axial extension, secondary body formation is completed, with somites, neural tube, and notochord development concluded. At this point, the pool of progenitor mesenchyme cells within the $\mathrm{CNH}$ is depleted by a combination of events: epiblast 
migration through the VER is complete, the non-proliferating mesenchyme that feeds into the $\mathrm{CNH}$ population is also depleted and the neuroblast cells originating in the $\mathrm{CNH}$ population have exited the cell cycle. Since most of these structures and cell populations are required for axial extension, the loss of nearly any one of them will halt progression of the tail. The vertebrate embryo hedges its bets, however, and has distinct concurrent mechanisms for terminating some if not all of these elements (Figure 5).

When somitogenesis is nearing completion, the rate of cell addition to and somite separation from the PSM begin to slow down. In the chick, the first 45 pairs of somites take 90 minutes each to form; thereafter, the segmentation clock slows such that the final 5 to 8 caudal somites (predecessors of the pygostyle) take 150 minutes to form [42]. One likely candidate for this deceleration is WNT3a. While somitogenesis is robustly proceeding, up to $\mathrm{HH}$ (Hamburger Hamilton [92]) stage 21, WNT3a is highly expressed in the tail mesenchyme, but as somite addition and the need for PSM nears its close, WNT3a is gradually downregulated between $\mathrm{HH} 22$ and $\mathrm{HH} 25$ [42]. RALDH2, an enzyme involved in the synthesis of RA from vitamin $\mathrm{A}$, is correspondingly upregulated in the tail mesenchyme in the chick and is thought to be responsible for WNT3a and FGF8 downregulation. This creates an imbalance of signaling factors, and thereby promotes the effects of RA. Exposing mouse embryos to increasing levels of RA induces more severe axial truncation (Figure 6A) [93]. In addition to contributing to the loss of the growth factor Fgf8, RA causes differentiation of somitic cells and concomitant reduction in cell division; without Wnt3a, these effects act as barriers to further somite addition. In the mouse, RA is also promoted by downregulation of Cyp26a1 [42], an enzyme that normally metabolizes RA [94]. When Cyp26a1 is downregulated, RA concentration effectively increases, further inhibiting tail growth [95,96]. Interestingly, a critical level of RA signaling is required, as either augmenting or decreasing the amount of RA causes premature termination of somitogenesis $[93,97,98]$. In this finely tuned system, RA is required for maturation of recently made somites before the next pair of somites can form, but prolonged exposure to RA prevents further somite addition. Wnt3a expression also affects somitogenesis via its cross-talk with the Notch pathway. Specifically, Wnt3a and Notch pathway genes regulate each others' expression levels and patterns [57,99-103], and Notch pathway genes are intrinsically tied to the segmentation clock and somite boundary formation $[47,48,104]$. As an indication of the coordination between these various pathways, loss of Fgf4 and Fgf8 in the mouse tail PSM results in loss of Wnt3a, downregulation of Notch signaling, and inhibition of Cyp26a1 [99], all of which act together to prematurely truncate the tail. Since Wnt3a also influences the expression of Fgf8 [103], downregulation of Wnt3a at the end of somitogenesis inhibits tail growth by influencing both RA effects as well as through inhibition of Notch-directed somite formation and maturation.

Changes in the VER occur as tail growth comes to an end, terminating notochord elongation, inhibiting somitogenesis [105], and also terminating caudal gastrulation [106]. The thickened ventral epithelium that characterizes the VER reaches its peak at approximately the 45-somite stage in the chick; subsequently, the VER gradually diminishes until it disappears altogether [105]. The dissipation of the VER is concomitant with loss of its signaling. Before the VER declines, it expresses several secreted proteins, including Sonic Hedgehog (Shh) [107], Fgf17, Bmp2, and Wnt5a $[105,108]$, and functions to control the expression of Noggin in overlying ventral mesoderm [106]. Noggin, in turn, is a powerful modulator of Bmps, and hence plays significant roles in Shh/Bmp signaling cascades. As the VER recedes, it can no longer maintain its signaling, and Noggin expression in ventral mesoderm is downregulated. When the VER is ablated, it prevents the ingression of epiblast cells that are needed for feeding cells into the non-proliferating mesenchyme of the tail and thus, the $\mathrm{CNH}$. The neural tube can temporarily extend without the presence of the notochord (albeit with ventral patterning abnormalities) [38,39], but somite formation and patterning are disrupted [40], and the tail prematurely truncates. Thus, the indirect effects of VER disruption affect the tail progenitor population and lead to termination of tail elongation.

Ablation studies, in which different axial structures are removed in a living embryo, have shed light on the interdependence of a number of these structures for axial extension. As mentioned above, VER or notochord ablation results in the failure to form the complete secondary neural tube and caudal somites, and leads to premature axial truncation. In studies where the neural tube was ablated, the dermamyotome region of differentiated somites was absent, likely due to disruptions in Bmp and Wnt signaling from both the dorsal neural tube and overlying dorsal ectoderm [109]. Removal of the $\mathrm{CNH}$ population causes subsequent loss of neural tube, notochord, somite formation inhibition and shortened tails $[39,43]$. If the somites themselves are removed, neural crest cell delamination and subsequent migration come to a halt; an imbalance between Noggin and Bmp4 is thought to be responsible [110]. Reminiscent of the balance between Wnt3a, Fgf8 and RA, there is also a balance between Noggin, Shh and Bmps between different structures in the tail. The opposing functions of these proteins help to pattern the neural tube [111] and are also involved in somite segmentation and differentiation [112]. Disruption of this balance 


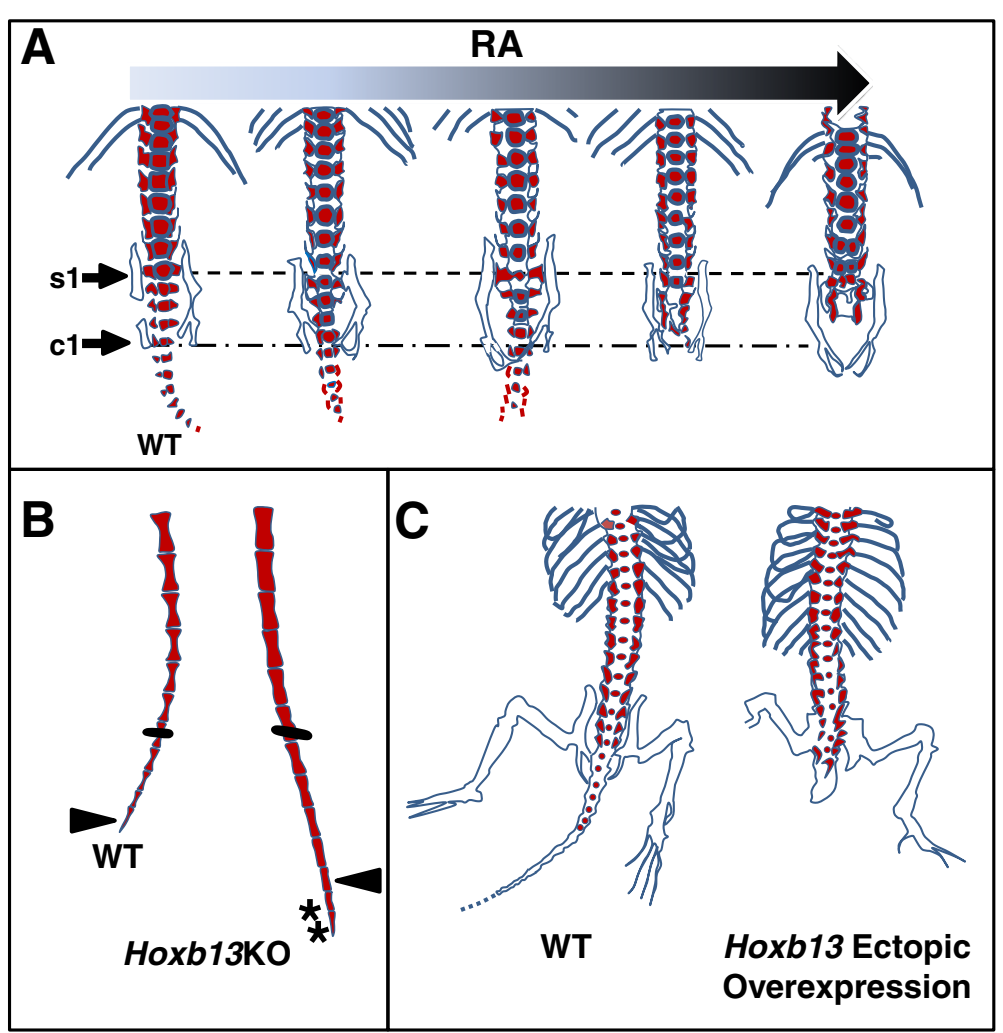

Figure 6 Experimental manipulations affecting the length of the vertebrate tail. (A) Increasing RA exposure in mouse embryos leads to progressive loss of caudal and sacral vertebrae. $s 1$ indicates first sacral vertebrae and c1 indicates first caudal vertebrae. Data adapted from Shum et al. 1999 [93]. (B) Hoxb13 knockout (Hoxb13KO) in the mouse increases caudal vertebrae number by 2 and causes more barrel-shaped as opposed to hourglass-shaped vertebrae. Bars indicate experimental marking of equivalent numbered vertebrae; arrowheads indicate caudal vertebra \#30 in both wildtype (WT) and Hoxb13KO; asterisks indicate two additional caudal vertebrae. Data adapted from Economides et al. 2003 [90]. (C) Precocious ectopic overexpression of Hoxb13 in the mouse causes prematurely truncated tails. Data adapted from Young et al. 2009 [81]. RA, retinoic acid.

likely plays multiple roles in terminating elongation of the tail.

Applying information from all of these ablation studies to the normal process of tail termination has helped us to understand why the disruption of one structure leads to the termination of others, and helps to explain why peripheral and motor nerves are missing at the end of the tail. Just as Noggin is upregulated with somite ablation, it is also upregulated in the dorsal neural tube at the end of the naturally waning tail. This enhanced expression is thought to inhibit neurogenic neural crest derivatives, causing loss of peripheral nerves [113]. Lack of motor neurons just anterior to the end of the tail is likely due to termination of the neural tube (from which motor neurons derive [114]), the loss of Shh signaling from the notochord and neural tube [115], which is required to pattern the motor neurons in the ventral neural tube, and/or the presence or absence of an as-yet unidentified diffusible signal intrinsic to the tail [116].

Another process involved in tail cessation is apoptosis, or programmed cell death. Apoptosis is a mechanism employed by embryos to help sculpt morphological features and cull extraneous cells, and is often considered to be a default pathway for those cells that find themselves within inappropriate environments. During axial extension, apoptosis is kept at bay at least in part by survival promoting signals through the Shh/Noggin/Bmp cascade [39,117], but this cascade is largely disrupted as tail growth slows. At these later stages, there is considerable cell death in the tail bud [118], which depletes the available pool needed for somite production. Signaling from Wnt3a and Fgfs is necessary for maintaining the pool of undifferentiated PSM cells which give rise to somites [55,119], and downregulation of these pathways in the waning tail contributes to apoptosis. In higher vertebrates, this severe reduction in PSM, however, is caused only in part by apoptosis. Due to RA effects, there is reduced cell division [42,120], and neuroblast cells exit the cell cycle, further depleting the progenitor population. However, PSM has not been completely eradicated before the segmentation oscillator comes to a halt, and the remaining PSM becomes unresponsive to 
signals that promote axial extension [42]. The concept that apoptosis plays a contributing but not solitary role in tail cessation is further substantiated by the fact that significant mesenchyme cell death occurs even while the tail is robustly extending [121], and apoptosis has been inhibited in different vertebrates, but longer tails have not been documented [122].

Finally, the prescribed species-specific number of somites that are formed is controlled by Hox genes [123,124], and the most caudally-expressed Hox genes act to terminate tail elongation. Precocious over-expression of Hox 13 paralogs at the posterior end of mouse [81] and chick [125] embryos leads to prematurely truncated tails with loss of caudal vertebrae (Figure 6C). Conversely, targeted knockout of Hoxb13 in the mouse leads to expansion of tail structures, including neural tube, PSM, and two extra caudal vertebrae (Figure 6B). A reduction in the level of apoptosis in PSM was also observed in these knockout mice, which ties Hox 13 genes to depletion of the mesenchyme cells needed for somitogenesis. In this same study, Hoxb13 was also shown to inhibit neuronal proliferation, which, combined with the normal loss of caudal neural crest-derived neurogenic cells, doubly ensures the lack of spinal ganglia at the end of the tail [90]. Another potential mechanism Hox13 genes employ to terminate the tail is to intersect the Wnt/Fgf/RA gradient by downregulating Cyp26a1 [81], providing yet another example of the level of involvement of this gradient on tail cessation.

To summarize, perturbations in virtually any of the tail elongation processes described above lead to termination of extension, and numerous perturbations are built into the axial extension system to ensure proper tail length. Imbalances in the Wnt/Fgf/RA and Noggin/Shh/Bmp gradients are largely responsible for stopping tail growth. Once disrupted, the signaling cascades generated from the gradients no longer properly coordinate with other cascades such as Notch, thereby disabling the elongation machinery. Hox13 paralog genes further inhibit tail elongation, likely through their interactions with the regulatory factors that control these gradients [81]. Finally, increased apoptosis at the termination of somitogenesis removes all remaining progenitor cells. All of these coordinating pathways are orchestrated through the different tail structures, and signaling between the structures maintains their inter-dependence so that if even one structure fails, the rest eventually follow suit. Species-specific differences in the way the orthologous pathways are modulated likely account for the varying tail lengths observed among vertebrates [123,124].

\section{Skeletal development of the bird synsacrum and tail}

Following the formation of somites that will contribute to the synsacrum, an axial structure with 14 fused thoracic (1), lumbar (6), sacral (2) and sacro-caudal (5) vertebrae (Figure 7) [126] (in chick, there is no evidence that caudal vertebrae are incorporated into the synsacrum [88]), the chick tail achieves its maximum number of somites by E5. Although the synsacral somites form as separate blocks of tissue, the chondrified synsacral cartilages fuse together to form a continuous structure, devoid of intervertebral discs. Distinct ossification centers for each of the vertebrae are retained, with the onset of ossification observed in a rostral to caudal sequence from E15 onward (Figure 7). In addition to the centrum of the vertebrae, the free sternal ribs have ossification centers. The lumbar vertebrae that follow have transverse processes, but these do not have independent ossification centers, rather ossifying from the pedicle situated between the centrum proximally and the transverse processes distally. The ventral processes abut and become fused to the ilium. Notably, the transverse dorsal processes and dorsal ligament uniting the lumbar vertebrae ossifies postnatally forming a continuous plate of bone, or sacral shield (Figure 7, adult). This is a common feature of birds from neornithines to modern birds, helping to strengthen the fused synsacrum [1]. The rigid synsacrum and ilium fuse to form an immovable structure with osteoblasts visible in the ilium from E14. The transverse and ventral processes of the two sacral vertebrae abut and fuse to the medial posterior curve of the ilium. These processes are sometimes referred to as sacral ribs, having their own ossification centers, similar to sternal ribs [127]. Beyond the synsacrum, the free caudal vertebrae develop ossification centers at E18, and finally, by E19 the fused cartilaginous elements of the pygostyle follow suit (not shown). Ossification of the axial vertebrae and pelvic girdle is complete by hatching [126]. Extending beyond the synsacrum, the mature tail in the chick consists of 5 to 6 free caudal vertebrae (there are 5 to 8 free caudal vertebrae among birds in general) and the pygostyle (a fusion of the final 5 to 6 somites).

\section{Mutations that cause tail truncation}

Relating the developmental events of axial extension and termination back to the process of evolution, one needs to consider birds as organisms that sustained one or more mutations that converted long theropod tails to short avian tails terminating in a fused, distal pygostyle. Considering the many redundancies in the process of tail cessation, it follows that just one mutation could have truncated the posterior axis. Alternatively, the short, fused tails of early birds could have been the result of a suite of mutations that occurred over a longer period of time, and the fossil record is incomplete. Complicating the genetics behind the transition to short-tailed birds is the nature of the mutations that could have occurred. Mutations can occur within gene coding sequence, in cis 


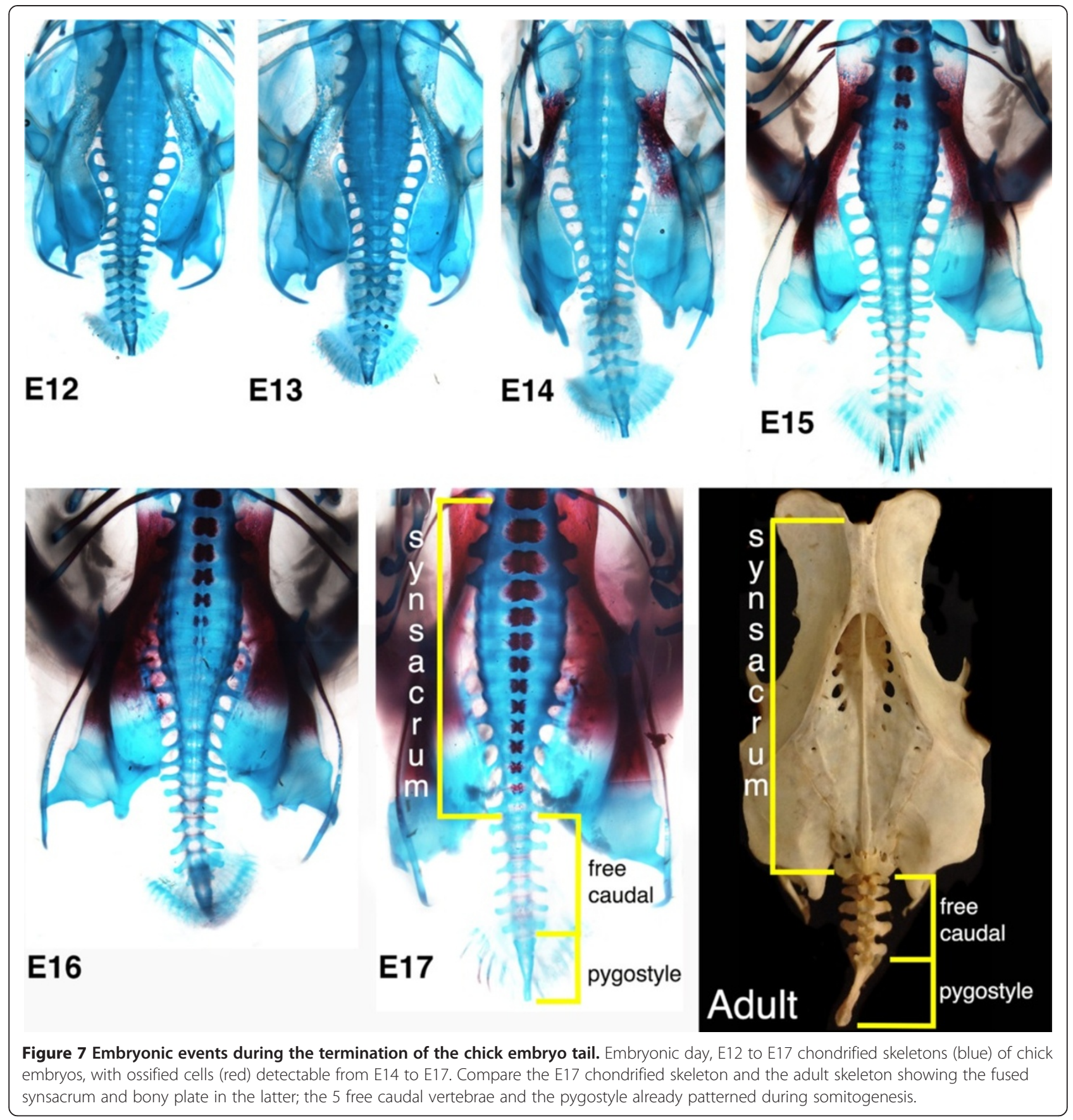

regulatory regions (CREs) outside coding sequence that control gene expression, by DNA deletion, or by gene duplication [128-130]. The prevailing theory is that most phenotypic changes in evolution are due to changes in CREs [128]. Alterations in the regulation of gene expression would allow for fewer pleiotropic and potentially deleterious effects of critical genes, by affecting some but not all expression patterns. Despite the potentially higher chance that changes in CREs were responsible for short fused tails, any of the other above-mentioned mechanisms were possible. It remains to be asked, given the lack of dinosaur DNA, how can we parcel out those mutations that affect morphological changes in the tail and may have converted theropod tails to bird tails?

One way to study the ancestral ties between organisms is to proceed with an evolutionary developmental biology or 'evo-devo' approach. This approach is particularly appealing when studying theropod-to-bird evolution, because despite the lack of dinosaur DNA, we can still examine gene pathways that potentially generated 
dinosaur traits. In terms of tail morphology, the gene pathways that are involved in tail elongation and termination in different organisms can be studied side-by-side, and modulations of those pathways that generate long versus short tails can be compared. In considering the many pathways involved in tail elongation and cessation, how do we narrow down the list of candidate genes that may have been modulated by mutation? For this particular study, we looked to the mouse, the vertebrate organism with the greatest accumulated data on mutations. Most mouse mutational data has been generated by targeted gene disruption, which causes phenotypes that are likely more extreme than mutations that would occur in, say, CREs. Despite the preponderance of targeted transgenesis, substantial mutational information has also been contributed by chemical, radiological, or transposon induction of random mutations, as well as by studies of spontaneous mutations. However the mutations occurred, the mouse is a reasonable place to begin the examination of those genes whose modulation affects tail morphology.

\section{Morphological analysis of mouse mutants}

A list of mouse tail mutants was generated from the MGI Jackson Laboratories database [131] and the literature [see Additional files 1 and 2]. From this list, a number of interesting and surprising correlations surfaced. Immediately obvious was the observation that of the 159 mutants with affected tails, only two, the Hoxb13 (Figure 6B) and $S l \times 4$ knockout mice, have increased numbers of caudal vertebrae, and these mutations cause only modest increases. Indeed, the tail suffers from a particular developmental precariousness, as seen in the preponderance of mutations causing short tails, suggesting that tail growth is relatively easily disrupted. While this remains to be studied across vertebrates, in this particular case, one could propose the argument that the early decoupling of the tail from hind limb locomotion in maniraptoran theropods may have facilitated tail reduction through a process of relaxed purifying selection. Relaxed purifying selection has been demonstrated to promote phenotype plasticity [132], and thus, may also facilitate rapid evolutionary change. The distal portion of the tail, once completely decoupled from hind limb function, may have been relatively free to accumulate mutations without deleterious effects and thereby facilitate the evolution of novel morphologies, namely a radically shortened tail and pygostyle.

To correlate the mouse mutants with specific skeletal differences observed between theropods, primitive birds and modern birds, several parameters were taken into consideration. When modern bird tails are compared with those of their more primitive bird or non-avian theropod ancestors, there are three primary differences: reduction in the number of caudal vertebrae, shortening of the caudal vertebral bodies, and fusion of the most distal caudal vertebrae into the pygostyle [25]. Bone fusion is indeed highly evident in the modern bird skeleton. Fusions are observed not just in the pygostyle, but also in the synsacrum and in the dorsal vertebrae anterior to the synsacrum, between the ribs as cross bridges called uncinate processes, and in the distal limbs. Between 150 and 120 million years ago, long before the Cretaceous Tertiary Extinction, these modern bird traits were evolving in primitive birds and other maniraptoran dinosaurs, and a number of variations of these traits have been observed in fossil specimens from this timeframe [2]. From the accumulated list of short-tailed mouse mutants, it is evident that most mutations affected more than just the tail, and a whole host of other pleiotropic defects were also observed, including, among others, more anterior bone fusions [see Additional file 1]. The question then becomes, are there any morphological traits that co-segregate with reduced numbers of caudal vertebrae for single mutations, and do any of these traits co-segregate in the fossil record? Fusions between various vertebral surfaces are observed in the bird skeleton, so different types of fusions were considered. Among the mouse mutants with decreased numbers of caudal vertebrae $(n=105)$, it was interesting to note that $34 \%(36 / 105)$ also displayed vertebral fusions (including fusions of neural arches, articular surfaces/zygopophyses, transverse processes, spinous processes, or vertebral bodies). Of the 36 with vertebral fusions, $53 \%$ had fused ribs. Of all mutants with decreased numbers of caudal vertebrae, only three also had digit fusion, which does not constitute a significant degree of co-segregation but indicates that digit fusion is also possible with truncated tail mutations.

Because modern and primitive short-tailed birds exhibit both truncated tails and fused vertebrae [1,2], we asked the opposing question: If a mouse mutation transpired which caused caudal vertebral body fusion (the predominant type of vertebral fusion observed in the pygostyle of modern and short-tailed primitive birds), what was the chance that caudal vertebrae number was also decreased? Seventeen of 23 caudal vertebral body fusion mutants, or $74 \%$, also had truncated tails (Table 1). A high percentage of caudal vertebral body fusion mutants (48\%) also displayed fused ribs. Thus, in the mouse, if a caudal vertebral body fusion event occurred, there was a nearly even chance the mouse also had fused ribs and a significantly better than even chance that it also had a truncated tail (for a complete list of mouse posterior vertebral fusion mutants and additional information on the caudal vertebral fusion mutants, see Additional files 2 and 3). Since there is a fairly high correlation of vertebral fusion, rib fusion, and truncated tails with mouse mutants, we next asked whether these traits also co-segregate in the fossil record in the transition from non-avian 
Table 1 Caudal vertebral body fusion mouse mutants

\begin{tabular}{|c|c|c|c|c|c|c|c|c|c|c|c|c|c|}
\hline \multirow[t]{2}{*}{ Mutant } & \multicolumn{5}{|c|}{ Affected vertebrae $^{a}$} & \multirow[t]{2}{*}{ cdl $v \#^{\mathbf{b}}$} & \multirow[t]{2}{*}{ Fused ribs } & \multirow[t]{2}{*}{ Fused digits } & \multicolumn{4}{|c|}{ Structure affected } & \multirow{2}{*}{$\begin{array}{l}\text { Relevant } \\
\text { pathways }\end{array}$} \\
\hline & $\mathrm{C}$ & $\mathrm{T}$ & $\mathrm{L}$ & $S$ & cdl & & & & So & NT & NC & VER & \\
\hline Ankrd13a & & & & & $\checkmark$ & & & & & & & & $\mathrm{Nd}$ \\
\hline Cenpj & & & & & $\checkmark$ & & & $\checkmark$ & & & & & $\mathrm{Nd}$ \\
\hline CREB & $\checkmark$ & $\checkmark$ & $\checkmark$ & & $\checkmark$ & & $\checkmark$ & & $\checkmark$ & & & & Notch/Wnt \\
\hline Dkk1 doubleridge/null & & & $\checkmark$ & $\checkmark$ & $\checkmark$ & & & $\checkmark$ & $\checkmark$ & & & & Wnt \\
\hline D/13 & $\checkmark$ & $\checkmark$ & $\checkmark$ & $\checkmark$ & $\checkmark$ & ++ & $\checkmark$ & & $\checkmark$ & & & & Notch/Wnt \\
\hline$f$ flexed tail; Sfxn 1 mutation & & & $\checkmark$ & $\checkmark$ & $\checkmark$ & $+/-$ & $\checkmark$ & & & $\checkmark$ & $\checkmark$ & & $\mathrm{Bmp} / \mathrm{Shh}$ \\
\hline Fgf3 & & & & & $\checkmark$ & ++ & & & $\checkmark$ & $\checkmark$ & & & Notch/Wnt \\
\hline Hes7 & $\checkmark$ & $\checkmark$ & $\checkmark$ & $\checkmark$ & $\checkmark$ & ++ & $\checkmark$ & & $\checkmark$ & & & & Notch/Wnt \\
\hline Ikka & $\checkmark$ & & & $\checkmark$ & $\checkmark$ & + & & $\checkmark$ & & & & & Notch; FGF \\
\hline Jsr jumbled spine and ribs & & $\checkmark$ & & & $\checkmark$ & ++ & $\checkmark$ & & $\checkmark$ & & & & Notch/Wnt \\
\hline Knk kinked tail & & & & & $\checkmark$ & + & & & & & $\checkmark$ & & Notch; Wnt \\
\hline Lrp6 crooked tail & & & & & $\checkmark$ & ++ & $\checkmark$ & & $\checkmark$ & $\checkmark$ & & & Notch/Wnt \\
\hline mea meander tail & & $\checkmark$ & $\checkmark$ & $\checkmark^{*}$ & $\checkmark$ & ++ & & & & & & & Wnt \\
\hline Meox1/Meox2 & & & & & $\checkmark$ & ++ & $\checkmark$ & & $\checkmark$ & & & & Retinoic Acid \\
\hline Noto & & & $\checkmark$ & $\checkmark$ & $\checkmark$ & ++ & & & $\checkmark$ & $\checkmark$ & $\checkmark$ & & Wnt \\
\hline Nrarp & & $\checkmark$ & $\checkmark$ & $\checkmark$ & $\checkmark$ & + & $\checkmark$ & & $\checkmark$ & & & & Notch/Wnt \\
\hline Ppp5c & & & & & $\checkmark$ & & & & & & & & Wnt \\
\hline Ror2 & & & & & $\checkmark$ & + & $\checkmark$ & $\checkmark$ & $\checkmark$ & & & & Notch/Wnt; Wnt \\
\hline Rp/38 & $\checkmark$ & $\checkmark$ & & & $\checkmark$ & ++ & $\checkmark$ & & & $\checkmark$ & & & Hox \\
\hline Rps7 & & & & $\checkmark^{*}$ & $\checkmark$ & + & & & & & & & nd \\
\hline Sulf1/sulf2 & & $\checkmark$ & $\checkmark$ & $\checkmark$ & $\checkmark$ & & & & $\checkmark$ & & & & Bmp/Shh \\
\hline Vangl2 & & $\checkmark$ & $\checkmark$ & $\checkmark$ & $\checkmark$ & ++ & $\checkmark$ & & & $\checkmark$ & & & Wnt \\
\hline Wnt5a & & & & $\checkmark$ & $\checkmark$ & +++ & & & $\checkmark$ & $\checkmark$ & & $\checkmark$ & Wnt \\
\hline
\end{tabular}

Selected phenotypes and relevant genetic pathways for each mutant are indicated. ${ }^{\mathrm{a}}$ Asterisks indicate fusion other than vertebral body fusion. ${ }^{\mathrm{b}}$ For the decreased number of caudal vertebrae (Cdl vertebrae \#) column, + less than half of the tail is absent; ++: half or more of the tail is absent; and +++: tail is severely truncated. Check marks indicate the presence of a particular trait. For a more comprehensive list of posterior vertebral body fusion mouse mutants (those which have fusions posterior to the cervical vertebrae, as seen in modern birds), and for more information on the caudal vertebral body mutants, see Additional files 2 and 3. Abbreviations: C, cervical; cdl, caudal; L, lumbar; NT, neural tube; NC, notochord; nd, not determined; S, sacral; So, somite; v, vertebrae; VER, ventral ectodermal ridge.

maniraptorans and primitive long-tailed birds to shorttailed birds.

Correlations between certain maniraptoran traits have been noted before, especially the co-incidence of short tails and the presence of a pygostyle [133]. The co-segregation of short tails and a pygostyle applies to a wide range of feathered non-avian maniraptorans and primitive birds, lending credence to the possibility that the traits are pleiotropic and linked by a single mutational event, irrespective of adaptive advantage. This is not to suggest that the same mutation occurred in these different groups; the number of different mouse mutants with these traits indicates that a number of different genes were likely causative. It should be noted that not all dinosaurs with a pygostyle had short tails (for example, Beipiaosaurus [134]). These long-tailed dinosaurs with a pygostyle, however, were in the minority, just as are the mouse mutants with fused distal vertebrae and unaffected tail length.
In the mouse mutants analyzed, vertebral fusions were correlated not just with short tails, but also with fused ribs. Rib fusions are likely observed with these mutations because somitogenesis is the most common developmental event affected, and vertebral ribs arise from somites [135-138]. If rib fusions were coincident with a vertebral fusion mutation, they could have altered the axial skeleton in a few different ways. Very proximal rib fusions could have helped establish the wide dimensions of the ilium (synsacrum) by increasing bone mass at the point ribs attach to the axial skeleton. Very distal rib fusions could also have increased the breadth of the sternum, as seen in the Gnai3 mouse mutant [139]. Branching of ribs is occasionally observed in some mutants, such as Tbx6 [140,141] [see Additional file 3], which could have been the mechanism behind the formation of uncinate processes. This possibility seems less likely, however, considering that quite a number of non-avian theropods exhibited uncinate processes with long tails and 
no pygostyle, such as Oviraptor philoceratops, Velociraptor mongoliensis, and Diononychus antirrhopus. Also, Sapeornis had a short tail with a rod-like pygostyle and no uncinate processes [21]. Even if uncinate processes had already evolved through separate means, however, we hypothesize their fusion to adjacent ribs (seen only in Aves [23]) could have been facilitated through a vertebral fusion mutation.

\section{Genetic analysis of mouse mutants}

Investigation into the genetic pathways that are modulated by these caudal vertebral body mutations in the mouse also proved insightful (Table 1 and [see Additional file 3]). Of the 20 (of 23) mutations whose affected pathways were previously studied, 10 involve Notch or Notch/Wnt signaling. The remaining mutations have the following pathway associations: seven involve Wnt signaling (possibly independent of Notch), two are associated with BMP/Shh cascades, and one each is involved in Hox or RA signaling. The genes that were mutated appear to have developmental roles that would be expected, which include functions in somitogenesis (most prevalent), neural tube and notochord biogenesis and patterning, mesoderm establishment and maintenance, neurogenesis, angiogenesis, and VER signaling. Of those associated with the Notch pathway, the majority $(6 / 10)$ were involved in somite segmentation or differentiation; these include CREB, Dll3, Fgf3, Hes7, Lrp6, and Nrarp. It is intriguing to note that in the chick, the Notch pathway members Lnfg, Nrarp, and Meso (the chick homolog of Mesp2), are all downregulated as somitogenesis slows [42], at an equivalent point at which the mouse tail would still be actively extending. Interestingly, several mutations among members of this particular pathway, including Dll3, Hes7, Lnfg, Lrp6 [142], Mesp2, and Tbx6, are reasonably well tolerated and cause spondylocostal dystosis (SCD) disease in humans [3]. Individuals suffering from this disease display fused ribs and vertebrae with unaffected reproductive capacity, as in the mouse mutants.

\section{Experimental manipulations and one spontaneous mutation that affect chick tail morphology}

As in other vertebrate species, the chick tail is often neglected as a focus of research. There are, however, additional studies that deserve mention here apart from the RA and Hox $13 a$ manipulations already cited. To date, targeted transgenesis in the bird is largely unreported, and even transgenic overexpression has been restricted to a small handful of genes. Genes or proteins can be modulated in other ways, however, and the chick embryo is amenable to studies such as microinjection, electroporation of DNA or RNA, viral transfection, and insertion of matrices soaked with diffusible proteins or other factors. The specific morphological changes upon ectopically applied RA in the tailbud are particularly interesting.
In addition to posterior truncation, stretches of accessory neural tube and notochord occur when RA is injected into the tailbud, indicative of enhanced neural differentiation [143]. Premature neural differentiation is evident in a number of the mouse mutants with truncated tails [see Additional file 1] and is also evident in the rumpless Araucana chicken [144]. To our knowledge, no manipulations in the bird have resulted in longer tails with increased numbers of caudal somites/vertebrae. One study attempted to extend neural crest in chick embryo tails by inhibiting Noggin [113]. While certain neural crest markers were indeed upregulated at the end of the tail, additional somites were not added and tail length remained unchanged. Just as in the mouse, manipulations in the tail are far more likely to reduce or otherwise fail to alter length as opposed to increase tail length.

The only known spontaneous mutation that truncates the avian axial skeleton, namely in the rumpless Araucana chicken (Figure 8A), was identified as a gainof-function mutation of the proneural (Iroquois) Irx 1 and Irx2 genes [145]. Iroquois genes are tied to Notch, Wnt, and Bmp/Shh signaling [146-148], and in addition to their proneural role, they establish tissue borders during development. Interestingly, heterozygotes of the rumpless locus retain 2 to 4 caudal vertebrae, and these are irregularly fused (Figure 8B) $[149,150]$, adding this mutation to those that cause both short tails and fused vertebrae. The most caudal somites are never generated and the pygostyle, therefore, never forms. While there is no equivalent gainof-function mouse mutant, loss-of-function mutations in either Irx 1 or $\operatorname{Ir} x 2$ in the mouse do not cause posterior truncation or fused vertebrae, emphasizing an important caveat with this study that mutation of the same genes can be manifested differently depending on the nature of the mutation.

It was previously estimated that among a variety of normal-tailed chicken breeds, a tailless phenotype was consistently observed in approximately one out of every thousand chicks hatched, making further tail truncation a relatively common chicken mutant phenotype [151]. Well-tolerated, relatively common tail truncating mutations (especially if dominant and germ-line) that conferred certain advantages would theoretically promulgate the evolutionary transition from long- to short-tailed birds.

\section{Additional considerations}

If a single mutation occurred that shortened the tail and fused the distal caudal vertebrae in short-tailed primitive birds, it would seem logical that occasionally, that gene modulation would spontaneously reverse resulting in more recent long-tailed birds. Several lines of evidence contradict this possibility, however. First, while not impossible, direct reversals of mutations are extremely unlikely. Indirect 


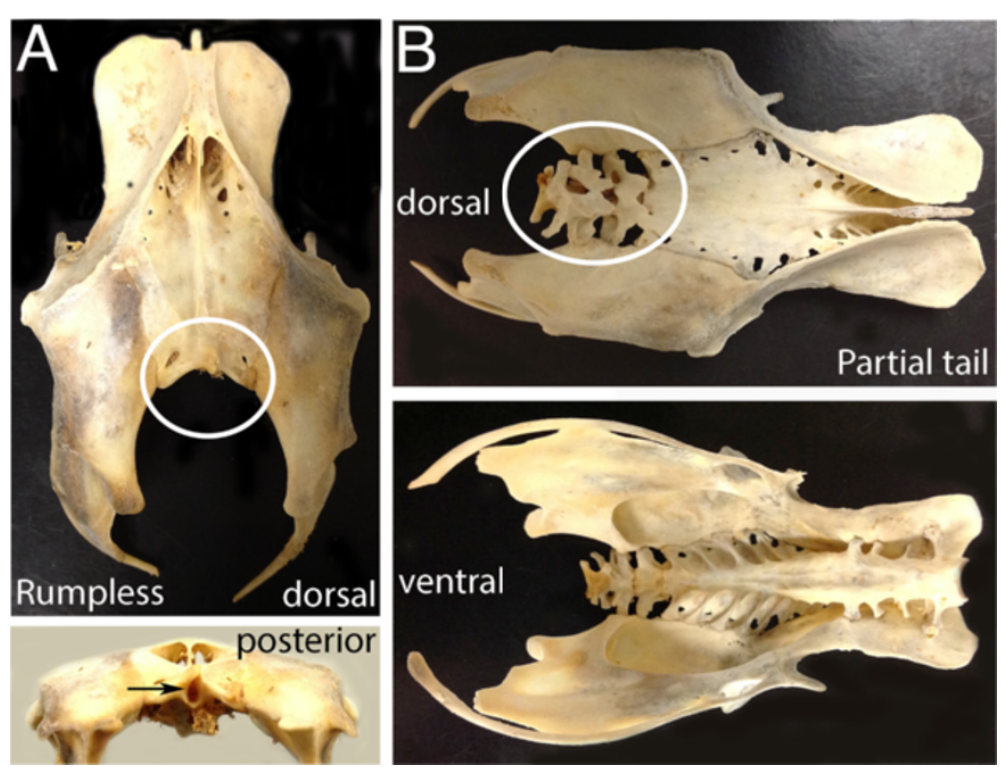

Figure 8 The Araucana rumpless chicken mutant. Adult skeletons showing the pelvis, synsacrum and caudal vertebrae. (A) In the homozygous mutant no caudal vertebrae develop (circle). The synsacrum develops normally and the bony plate over the fused vertebrae forms as expected. There is a hole in the final vertebra leaving the neural tube exposed. (B) In the heterozygote, 2 to 4 fused elements form beyond the synsacrum, in place of the free caudal vertebrae.

mutations that would re-activate a particular pathway are possible but also unlikely, considering the mutation(s) would have to reintroduce the fine balance of factors required for axial extension without being detrimental. Second, Dollo's law states that accumulation of mutations over time, especially for those genes whose functions are no longer selected for, can prohibit certain morphological traits from resurfacing [152]. Birds with fully formed teeth, for example, have never been observed in modern times because the genes for enamel, no longer selected for, were inactivated in the bird genome $[153,154]$. Third, since long tails hinder flight, and flight mechanics evolved primarily with short tails [36], reintroduction of long tails would have likely impeded survival. Lastly, traits that influence sexual selection cannot be underestimated. The appearance of the pygostyle, possibly with the fan-shaped array of mobile tail feathers, may have indelibly affected mate choice among birds, which would have ensured the persistence of the pygostyle phenotype.

The ramifications to a long-tailed bird that suddenly lost the bulk of its tail also need to be considered. An anterior shift of its center of mass would likely have impacted flight and terrestrial locomotion. Hutchinson, however, postulated that the reduction of the caudofemoralis muscle in primitive short-tailed birds would not have impeded them from being very capable runners [155]. Also, an anterior shift of the center of mass, observed in primitive and modern birds, is modeled to facilitate flight [30].

\section{Conclusions}

We have no way of knowing at this point, of course, what or how many mutations occurred in early bird evolution, or even which was the true basal ancestor that sustained the initial mutations. Despite the many caveats with this approach, however, our analyses of genetic and fossil evidence suggest the possibility that a single mutation could have occurred in a paravian dinosaur, which both truncated its tail and fused its distal caudal vertebrae into a pygostyle. Whether there were one or multiple mutations it should be noted that of the 37 posterior vertebral body-fusion mutants we examined [see Additional file 3], all but four are known to be caused by single mutational events, and have substantial phenotypic alterations not just to the tail, but to other parts of the skeleton as well. On the other hand, it should also be noted that most of the mutants that were considered for this study have mutations within gene coding regions. Mutations in CREs would likely have resulted in fewer pleiotropic effects in both mice and early birds. The nature of potential pleiotropic effects, however, should still be considered when addressing the issue of evolutionary morphological change. In this case, the pleiotropic effects of vertebral body mutations mirror a number of alterations observed in early birds, and these additional alterations occurred in the same timeframe as the transition to truncated tails. Since these pleiotropic effects (at least in the mouse) include fused vertebrae, not just in the tail but also in more anterior regions, the more 
substantial synsacral fusions observed in confuciusornithids, enantiornithines, and ornithurines could have been facilitated by a vertebral body mutation (or convergently by a similar mutation). Additional rib or uncinate process fusion, or even digit fusion, could also have occurred, which together with the other bone fusion and tail truncation phenotypes, could account for the relatively sudden appearance of these short-tailed birds in the fossil record. Jeholornis and Confuciusornis were likely contemporaries [156], and Jeholornis exhibited flight structures very similar to Confuciusornis but differed considerably in the posterior half of its body [157]. If a vertebral fusion mutation occurred in a primitive bird like Jeholornis, which fused additional vertebrae in its synsacrum, truncated its tail, and fused some ribs, the resulting creature would have come a long way towards resembling Confuciusornis. Once the mutation(s) had occurred, it/they were likely fixed in the population by the advantages conferred on flight and possibly on sexual selection display.

If we were to conjecture what was a likely type of mutation that occurred in a feathered maniraptoran dinosaur on its way to becoming a bird, based on the mouse mutant data, we would hypothesize that one or more mutations modulated genes involved in axial extension. Any number of axial extension genes could have been affected, but in the mouse, most mutations causing distally fused caudal vertebrae and shortened tails lie in the Notch/Wnt pathway, in somite segmentation, differentiation or somite boundary formation. Future comparative studies of signaling cascades between birds, long-tailed reptiles and mice should help to uncover these long-lost mutations, and further our understanding of the evolution of birds from non-avian maniraptoran dinosaurs.

\section{Additional files}

Additional file 1: Excel spreadsheet of mouse tail mutants (16 pages). Additional file 2: Abbreviations and references for Additional files 1 and 3.

Additional file 3: Table of posterior vertebral body fusion mouse mutants.

\section{Abbreviations}

AER: apical ectodermal ridge; BMP: bone morphogenetic protein; CML: caudofemoralis muscle, large; $\mathrm{CNH}$ : chordoneural hinge; CREs: cis regulatory regions; E: embryonic day; FGF: fibroblast growth factor; HH: Hamburger Hamilton; M: mesenchyme; Nc: notochord; NT: neural tube; PSM: presomitic mesoderm; RA: retinoic acid; SCD: spondylocostal dystosis; Shh: sonic hedgehog; TG: tailgut; VER: ventral ectodermal ridge.

\section{Competing interests}

The authors declare that they have no competing interests.

\section{Authors' contributions}

DR performed the mouse tail mutant analysis, assembled the developmental axial extension and termination sections, designed Figures 2, 4 and 5, and was primarily responsible for writing the manuscript. SCC was responsible for the Araucana studies, Figures 7 and 8, and contributed to the writing of the manuscript. HCEL wrote the introduction and contributed to the section on bird tail development, and with DR, established the plan for the review. $\mathrm{CO}$ contributed to the introduction, and performed the analyses and subsequent execution of Figures 1 and 3. AB performed RA inhibition studies on chick embryo tails. CM is a co-PI for the overall project, and contributed to writing the manuscript. RB contributed to the mouse tail mutant analysis and to the review layout. $\mathrm{JH}$ is the $\mathrm{Pl}$, and spearheaded this project from its onset. JH provided details of the prevailing evolutionary theories discussed, and contributed to the project's direction. All authors critically edited the manuscript and approved it for submission.

\section{Authors' information}

DR is a post-doctoral fellow at the Museum of the Rockies, Montana State University, Bozeman, MT. SCC is an Associate Professor in the Department of Biological Sciences, Clemson University, Clemson, SC. HCEL is an Associate Professor at the Redpath Museum, McGill University, Montreal, Canada. CO is a Visiting Professor in the Department of Earth Sciences, Montana State University. AB is a Senior Research Assistant at Vaccine and Gene Therapy Florida, Port Lucie, FL; she was a former post-doctoral fellow at the Museum of the Rockies, Montana State University. CM is an Associate Professor in the Cell Biology and Neuroscience Department at Montana State University. RB is an Associate Professor in the Cell Biology and Neuroscience Department at Montana State University. JH is a Regents' Professor of Paleontology in the Department of Earth Sciences, Montana State University and is Curator of Paleontology at the Museum of the Rockies, Montana State University.

\section{Acknowledgements}

The authors wish to sincerely thank Michael Jones (Jones-Design.com) for the digital rendering of Figures 4 and 5. We also wish to thank Daniel Van Antwerp for his critical reading of the manuscript and Thomas Townsend for accumulating data on dinosaurs with a pygostyle. This project is entirely funded through private donations, and the authors wish to thank George Lucas, without whose contribution, this project would not have been possible.

\section{Author details}

'Museum of the Rockies, Montana State University, 600 West Kagy Blvd, Bozeman, MT 59717, USA. ²Department of Biological Sciences, Clemson University, 340 Long Hall, Clemson, SC 29634, USA. ${ }^{3}$ Redpath Museum, McGill University, 859 Sherbrooke Street W., Montreal, Quebec H3A 0C4, Canada. ${ }^{4}$ Department of Earth Sciences, Montana State University, 226 Traphagen Hall, Bozeman, MT 59717, USA. ${ }^{5}$ Current address: Vaccine and Gene Therapy FL, 9801 Discovery Way, Port Lucie, FL 34987, USA. ${ }^{6}$ Department of Cell Biology \& Neuroscience, Montana State University, 513 Leon Johnson Hall, Bozeman, MT 59717, USA.

Received: 2 May 2014 Accepted: 10 July 2014

Published: 29 July 2014

\section{References}

1. Chiappe LM, Witmer LM: Mesozoic Birds: Above the Heads of Dinosaurs. Berkeley, Los Angeles, and London: University of California Press; 2002.

2. Chiappe LM: Glorified Dinosaurs: The Origin and Early Evolution of Birds. Sydney, Australia or Hoboken. NJ USA: University of New South Wales or John Wiley \& Sons, Inc; 2007.

3. Giampietro PF, Raggio CL, Blank RD, McCarty C, Broeckel U, Pickart MA: Clinical, genetic and environmental factors associated with congenital vertebral malformations. Molecular Syndromology 2013, 4:94-105.

4. Gatesy SM: Caudofemoral musculature and the evolution of theropod locomotion. Paleobiology 1990, 16:170-186.

5. Chiappe LM: Aves. In Encyclopedia of Dinosaurs. Edited by Currie PJ, Padian K. San Diego: Academic Press; 1997:32-38.

6. Padian K: Avialae. In Encyclopedia of Dinosaurs. Edited by Currie PJ, Padian K. San Diego: Academic Press; 1997:39-40.

7. Sereno PC: The origin and evolution of dinosaurs. Ann Rev Earth Planetary Sci 1997, 25:435-489.

8. Gauthier J: Saurischian monophyly and the origin of birds. Memoirs of the California Academy of Sciences 1986, 8:55.

9. Huxley TH: On the animals which are most nearly intermediate between birds and reptiles. Annals \& Magazine of Natural History 1868, 2:66-75. 
10. Huxley TH: Further evidence of the affinity between the dinosaurian reptiles and birds. Q J Geol Soc 1870, 26:12-31.

11. De Beer G: Archaeopteryx lithographica. British Museum of Natural History London Publ 1954, 1-68.

12. Zhou Z, Zhang F: A long-tailed, seed-eating bird from the Early Cretaceous of China. Nature 2002, 418:405-409.

13. Persons S: Oviraptorosaur tail forms and functions. Acta Palaeontol Pol 2013.

14. Barsbold R, Currie PJ, Myhrvold NP, Osmolska H, Tsogtbaatar K, Watabe M: A pygostyle from a non-avian theropod. Nature 2000, 403:155-156

15. He T, Wang X-L, Zhou Z-H: A new genus and species of caudipterid dinosaur from the Lower Cretaceous Jiufotang Formation of western Liaoning, China. Vertebrate PalAsiatica 2008, 46:178-189.

16. Xu X, Zheng X, You H: Exceptional dinosaur fossils show ontogenetic development of early feathers. Nature 2010, 464:1338-1341.

17. Zhang F, Zhou Z, Xu X, Wang $X$, Sullivan C: A bizarre Jurassic maniraptoran from China with elongate ribbon-like feathers. Nature 2008, 455:1105-1108.

18. Wellnhofer P: Archaeopteryx: Icon of Evolution. Munich: Verlag Dr. Friedrich Pfeil; 2009.

19. He HY, Wang $X L$, Zhou ZH, Wang F, Boven A, Shi GH, Zhu RX: Timing of the Jiufotang Formation (Jehol Group) in Liaoning, northeastern China, and its implications. Geophys Res Lett 2004, 31, L12605.

20. Zhou Z, Zhang F: Largest Bird from te Early Cretaceous and Its Implications for the Earliest Avian Ecological Diversification. Die Naturwissenschaften 2002, 89:34-38.

21. Zhou Z, Zhang F: Anatomy of the primitive bird Sapeornis chaoyangensis from the Early Cretaceous of Liaoning, China. Can J Earth Sci 2003, 40:731-747.

22. Gao C, Chiappe LM, Meng Q, O'Connor JK, Wang X, Cheng X, Liu J: A new basal lineage of early Cretaceous birds from China and its implications on the evolution of the avian tail. Palaeontology 2008 51:775-791.

23. Codd JR: Uncinate processes in birds: morphology, physiology and function. Comp Biochem Physiol A Mol Integr Physiol 2010, 156:303-308.

24. Tickle PG, Ennos AR, Lennox LE, Perry SF, Codd JR: Functional significance of the uncinate processes in birds. J Exp Biol 2007, 210:3955-3961.

25. Gatesy SM, Dial KP: From frond to fan: Archaeopteryx and the evolution of short-tailed birds. Evolution 1996, 50:2037-2048

26. O'Connor J, Wang X, Sullivan C, Zheng X, Tubaro P, Zhang X, Zhou Z: Unique caudal plumage of Jeholornis and complex tail evolution in early birds. Proc Natl Acad Sci U S A 2013, 110:17404-17408.

27. Hasson O: Sexual displays as amplifiers: practical examples with an emphasis on feather decorations. Behav Ecol 1991, 2:189-197.

28. Landauer W, Dunn LC: Two types of rumplessness in domestic fowls. $J$ Hered 1925, 16:153-160

29. Chiappe LM: Anatomy and Systematics of the Confuciusornithidae (Theropoda: Aves) from the late Mesozoic of Northeastern China. Bull Am Mus Nat Hist 1999, no. 242:1-89.

30. Gatesy SM, Dial KP: Locomotor modules and the evolution of avian flight. Evolution 1996, 50:331-340.

31. Dececchi TA, Larsson HC: Body and limb size dissociation at the origin of birds: uncoupling allometric constraints across a macroevolutionary transition. Evolution 2013, 67:2741-2752.

32. Gatesy SM, Dial KP: Tail muscle activity patterns in walking and flying pigeons (Columba livia). J Expl Biol 1993, 176:55-76.

33. Thomas ALR: Why do birds have tails? The tail as a drag reducing flap, and trim control. J Theor Biol 1996, 183:247-253.

34. Maybury WJ, Rayner JM, Couldrick LB: Lift generation by the avian tail. Proc Biol Sci / The Royal Society 2001, 268:1443-1448.

35. Thomas ALR, Balmford A: How natural selection shapes birds' tails. Am Nat 1995, 146:848-868.

36. Maybury WJ, Rayner JM: The avian tail reduces body parasite drag by controlling flow separation and vortex shedding. Proc Biol SciThe Royal Society 2001, 268:1405-1410.

37. Choi KS, Cohn MJ, Harfe BD: Identification of nucleus pulposus precursor cells and notochordal remnants in the mouse: implications for disk degeneration and chordoma formation. Dev Dyn 2008, 237:3953-3958
38. Davidson LA, Keller RE: Neural tube closure in Xenopus laevis involves medial migration, directed protrusive activity, cell intercalation and convergent extension. Development 1999, 126:4547-4556.

39. Le Douarin NM: Early neurogenesis in Amniote vertebrates. Int J Dev Biol 2001, 45:373-378.

40. Huang R, Stolte D, Kurz H, Ehehalt F, Cann GM, Stockdale FE, Patel K, Christ B: Ventral axial organs regulate expression of myotomal Fgf- 8 that influences rib development. Dev Biol 2003, 255:30-47.

41. Schoenwolf GC, Chandler NB, Smith JL: Analysis of the origins and early fates of neural crest cells in caudal regions of avian embryos. Dev Biol 1985, 110:467-479.

42. Tenin G, Wright D, Ferjentsik Z, Bone R, McGrew MJ, Maroto M: The chick somitogenesis oscillator is arrested before all paraxial mesoderm is segmented into somites. BMC Dev Biol 2010, 10:24.

43. McGrew MJ, Sherman A, Lillico SG, Ellard FM, Radcliffe PA, Gilhooley HJ, Mitrophanous KA, Cambray N, Wilson V, Sang H: Localised axial progenitor cell populations in the avian tail bud are not committed to a posterior Hox identity. Development 2008, 135:2289-2299.

44. Handrigan GR: Concordia discors: duality in the origin of the vertebrate tail. J Anat 2003, 202:255-267.

45. Gruneberg $\mathrm{H}$ : A ventral ectodermal ridge of the tail in mouse embryos. Nature 1956, 177:787-788.

46. Gajovic S, Kostovic-Knezevic L: Ventral ectodermal ridge and ventral ectodermal groove: two distinct morphological features in the developing rat embryo tail. Anat Embryol 1995, 192:181-187.

47. Maroto M, Bone RA, Dale JK: Somitogenesis. Development 2012, 139:2453-2456.

48. Saga Y: The mechanism of somite formation in mice. Curr Opin Genet Dev 2012, 22:331-338.

49. Freitas C, Rodrigues S, Charrier JB, Teillet MA, Palmeirim I: Evidence for medial/lateral specification and positional information within the presomitic mesoderm. Development 2001, 128:5139-5147.

50. Dubrulle J, McGrew MJ, Pourquie O: FGF signaling controls somite boundary position and regulates segmentation clock control of spatiotemporal Hox gene activation. Cell 2001, 106:219-232.

51. Sawada A, Shinya M, Jiang YJ, Kawakami A, Kuroiwa A, Takeda H: Fgf/MAPK signalling is a crucial positional cue in somite boundary formation. Development 2001, 128:4873-4880.

52. Aulehla A, Wehrle C, Brand-Saberi B, Kemler R, Gossler A, Kanzler B, Herrmann BG: Wnt3a plays a major role in the segmentation clock controlling somitogenesis. Dev Cell 2003, 4:395-406.

53. del Corral DR, Storey KG: $g$ switch that controls differentiation and patterning onset in the extending vertebrate body axis. BioEssays 2004, 26:857-869.

54. Aulehla A, Wiegraebe W, Baubet V, Wahl MB, Deng C, Taketo M, Lewandoski $M$, Pourquie $O$ : A beta-catenin gradient links the clock and wavefront systems in mouse embryo segmentation. Nat Cell Biol 2008, 10:186-193.

55. Aulehla A, Pourquie O: Signaling gradients during paraxial mesoderm development. Cold Spring Harb Perspect Biol 2010, 2:a000869.

56. Palmeirim I, Henrique D, Ish-Horowicz D, Pourquie O: Avian hairy gene expression identifies a molecular clock linked to vertebrate segmentation and somitogenesis. Cell 1997, 91:639-648.

57. Ishikawa A, Kitajima S, Takahashi Y, Kokubo H, Kanno J, Inoue T, Saga Y: Mouse Nkd1, a Wnt antagonist, exhibits oscillatory gene expression in the PSM under the control of Notch signaling. Mech Dev 2004 121:1443-1453.

58. Dale JK, Malapert $P$, Chal J, Vilhais-Neto G, Maroto M, Johnson T, Jayasinghe S, Trainor P, Herrmann B, Pourquie O: Oscillations of the snail genes in the presomitic mesoderm coordinate segmental patterning and morphogenesis in vertebrate somitogenesis. Dev Cell 2006, 10:355-366

59. Dequeant ML, Glynn E, Gaudenz K, Wahl M, Chen J, Mushegian A Pourquie O: A complex oscillating network of signaling genes underlies the mouse segmentation clock. Science 2006, 314:1595-1598.

60. Niwa Y, Masamizu Y, Liu T, Nakayama R, Deng CX, Kageyama R: The initiation and propagation of Hes7 oscillation are cooperatively regulated by Fgf and notch signaling in the somite segmentation clock. Dev Cell 2007, 13:298-304. 
61. Bessho $Y$, Hirata H, Masamizu Y, Kageyama R: Periodic repression by the bHLH factor Hes7 is an essential mechanism for the somite segmentation clock. Genes Dev 2003, 17:1451-1456.

62. Dale JK, Maroto M, Dequeant ML, Malapert P, McGrew M, Pourquie O: Periodic notch inhibition by lunatic fringe underlies the chick segmentation clock. Nature 2003, 421:275-278.

63. Oates AC, Morelli LG, Ares S: Patterning embryos with oscillations: structure, function and dynamics of the vertebrate segmentation clock. Development 2012, 139:625-639.

64. Rida PCG, Le Minh N, Jiang Y-J: A Notch feeling of somite segmentation and beyond. Dev Biol 2004, 265:2-22.

65. Saga Y: Segmental border is defined by the key transcription factor Mesp2, by means of the suppression of Notch activity. Dev Dyn 2007, 236:1450-1455.

66. Oginuma M, Niwa Y, Chapman DL, Saga Y: Mesp2 and Tbx6 cooperatively create periodic patterns coupled with the clock machinery during mouse somitogenesis. Development 2008, 135:2555-2562.

67. Takahashi J, Ohbayashi A, Oginuma M, Saito D, Mochizuki A, Saga Y, Takada S: Analysis of Ripply1/2-deficient mouse embryos reveals a mechanism underlying the rostro-caudal patterning within a somite. Dev Biol 2010, 342:134-145.

68. Sasaki N, Kiso M, Kitagawa M, Saga Y: The repression of Notch signaling occurs via the destabilization of mastermind-like 1 by Mesp2 and is essential for somitogenesis. Development 2011, 138:55-64.

69. Krol AJ, Roellig D, Dequeant ML, Tassy O, Glynn E, Hattem G, Mushegian A Oates AC, Pourquie O: Evolutionary plasticity of segmentation clock networks. Development 2011, 138:2783-2792.

70. Mallo M, Wellik DM, Deschamps J: Hox genes and regional patterning of the vertebrate body plan. Dev Biol 2010, 344:7-15.

71. Heffer A, Pick L: Conservation and variation in Hox genes: how insect models pioneered the evo-devo field. Annu Rev Entomol 2013, 58:161-179.

72. Dressler GR, Gruss P: Anterior boundaries of Hox gene expression in mesoderm-derived structures correlate with the linear gene order along the chromosome. Differentiation 1989, 41:193-201.

73. Duboule D, Dolle P: The structural and functional organization of the murine HOX gene family resembles that of Drosophila homeotic genes. EMBO J 1989, 8:1497-1505.

74. Graham A, Papalopulu N, Krumlauf R: The murine and Drosophila homeobox gene complexes have common features of organization and expression. Cell 1989, 57:367-378.

75. Izpisua-Belmonte JC, Falkenstein H, Dolle P, Renucci A, Duboule D: Murine genes related to the Drosophila $A b d B$ homeotic genes are sequentially expressed during development of the posterior part of the body. EMBO J 1991, 10:2279-2289.

76. Gaunt SJ, Strachan L: Temporal colinearity in expression of anterior Hox genes in developing chick embryos. Dev Dyn 1996, 207:270-280.

77. limura T, Pourquie O: Collinear activation of Hoxb genes during gastrulation is linked to mesoderm cell ingression. Nature 2006 442:568-571.

78. Mallo M, Vinagre T, Carapuco M: The road to the vertebral formula. Int J Dev Biol 2009, 53:1469-1481.

79. Amores A, Force A, Yan $Y L$, Joly L, Amemiya C, Fritz A, Ho RK Langeland J, Prince V, Wang YL, Westerfield M, Ekker M, Postlethwait JH: Zebrafish hox clusters and vertebrate genome evolution. Science 1998, 282:1711-1714.

80. Forlani S: Acquisition of Hox codes during gastrulation and axial elongation in the mouse embryo. Development 2003, 130:3807-3819.

81. Young T, Rowland JE, van de Ven C, Bialecka M, Novoa A, Carapuco M, van Nes J, de Graaff W, Duluc I, Freund JN, Beck F, Mallo M, Deschamps J: $\mathrm{Cdx}$ and Hox genes differentially regulate posterior axial growth in mammalian embryos. Dev Cell 2009, 17:516-526.

82. Wellik DM, Capecchi MR: Hox10 and Hox11 genes are required to globally pattern the mammalian skeleton. Science 2003, 301:363-367.

83. Jurberg AD, Aires R, Varela-Lasheras I, Novoa A, Mallo M: Switching axial progenitors from producing trunk to tail tissues in vertebrate embryos. Dev Cell 2013, 25:451-462.

84. Brooke NM, Garcia-Fernandez J, Holland PW: The ParaHox gene cluster is an evolutionary sister of the Hox gene cluster. Nature 1998, 392:920-922.
85. van Rooijen C, Simmini S, Bialecka M, Neijts R, van de Ven C, Beck F, Deschamps J: Evolutionarily conserved requirement of $\mathrm{Cdx}$ for post-occipital tissue emergence. Development 2012, 139:2576-2583.

86. Mallo M, Alonso CR: The regulation of Hox gene expression during animal development. Development 2013, 140:3951-3963.

87. Ikeya M, Takada S: Wnt-3a is required for somite specification along the anteroposterior axis of the mouse embryo and for regulation of $\mathrm{cdx}-1$ expression. Mech Dev 2001, 103:27-33.

88. Burke AC, Nelson CE, Morgan BA, Tabin C: Hox genes and the evolution of vertebrate axial morphology. Development 1995, 121:333-346.

89. Knezevic V, De Santo R, Schughart K, Huffstadt U, Chiang C, Mahon KA Mackem S: Hoxd-12 differentially affects preaxial and postaxial chondrogenic branches in the limb and regulates Sonic hedgehog in a positive feedback loop. Development 1997, 124:4523-4536.

90. Economides KD, Zeltser L, Capecchi MR: Hoxb13 mutations cause overgrowth of caudal spinal cordand tail vertebrae. Dev Biol 2003, 256:317-330.

91. van den Akker E, Reijnen M, Korving J, Brouwer A, Meijlink F, Deschamps J: Targeted inactivation of Hoxb8 affects survival of a spinal ganglion and causes aberrant limb reflexes. Mech Dev 1999, 89:103-114.

92. Hamburger $\mathrm{V}$, Hamilton $\mathrm{HL}$ : A series of normal stages in the development of the chick embryo. J Morphol 1951, 88:49-92.

93. Shum AS, Poon LL, Tang WW, Koide T, Chan BW, Leung YC, Shiroishi T, Copp AJ: Retinoic acid induces down-regulation of Wnt-3a, apoptosis and diversion of tail bud cells to a neural fate in the mouse embryo. Mech Dev 1999, 84:17-30.

94. Ross AC, Zolfaghari R: Cytochrome P450s in the regulation of cellular retinoic acid metabolism. Annu Rev Nutr 2011, 31:65-87.

95. Abu-Abed S: Developing with lethal RA levels: genetic ablation of Rarg can restore the viability of mice lacking Cyp26a1. Development 2003, 130:1449-1459.

96. Sakai Y, Meno C, Fujii H, Nishino J, Shiratori H, Saijoh Y, Rossant J, Hamada H: The retinoic acid-inactivating enzyme CYP26 is essential for establishing an uneven distribution of retinoic acid along the anterio-posterior axis within the mouse embryo. Genes Dev 2001, 15:213-225.

97. Iulianella A, Beckett B, Petkovich M, Lohnes D: A molecular basis for retinoic acid-induced axial truncation. Dev Biol 1999, 205:33-48.

98. Janesick A, Nguyen TT, Aisaki K, Igarashi K, Kitajima S, Chandraratna RA, Kanno J, Blumberg B: Active repression by RARgamma signaling is required for vertebrate axial elongation. Development 2014, 141:2260-2270.

99. Boulet AM, Capecchi MR: Signaling by FGF4 and FGF8 is required for axial elongation of the mouse embryo. Dev Biol 2012, 371:235-245.

100. Wahl MB, Deng C, Lewandoski M, Pourquie O: FGF signaling acts upstream of the NOTCH and WNT signaling pathways to control segmentation clock oscillations in mouse somitogenesis. Development 2007, 134:4033-4041.

101. Hayashi S, Shimoda T, Nakajima M, Tsukada Y, Sakumura Y, Dale JK, Maroto M, Kohno K, Matsui T, Bessho Y: Sprouty4, an FGF inhibitor, displays cyclic gene expression under the control of the notch segmentation clock in the mouse PSM. PLOS One 2009, 4:e5603.

102. Gonzalez A, Manosalva I, Liu T, Kageyama R: Control of Hes7 expression by Tbx6, the Wnt pathway and the chemical Gsk3 inhibitor LiCl in the mouse segmentation clock. PLoS One 2013, 8:e53323.

103. Dunty WC Jr, Biris KK, Chalamalasetty RB, Taketo MM, Lewandoski M Yamaguchi TP: Wnt3a/beta-catenin signaling controls posterior body development by coordinating mesoderm formation and segmentation. Development 2008, 135:85-94.

104. Dubrulle J, Pourquie O: From head to tail: links between the segmentation clock and antero-posterior patterning of the embryo. Curr Opin Genet Dev 2002, 12:519-523.

105. Goldman DC, Martin GR, Tam PP: Fate and function of the ventral ectodermal ridge during mouse tail development. Development 2000, 127:2113-2123.

106. Ohta S, Suzuki K, Tachibana K, Tanaka H, Yamada G: Cessation of gastrulation is mediated by suppression of epithelial-mesenchymal transition at the ventral ectodermal ridge. Development 2007, 134:4315-4324. 
107. Daane JM, Downs KM: Hedgehog signaling in the posterior region of the mouse gastrula suggests manifold roles in the fetal-umbilical connection and posterior morphogenesis. Dev Dyn 2011, 240:2175-2193.

108. Gofflot F, Hall M, Morriss-Kay GM: Genetic patterning of the developing mouse tail at the time of posterior neuropore closure. Dev Dyn 1997, 210:431-445.

109. Spence MS, Yip J, Erickson CA: The dorsal neural tube organizes the dermamyotome and induces axial myocytes in the avian embryo. Development 1996, 122:231-241.

110. Sela-Donenfeld D, Kalcheim C: Inhibition of noggin expression in the dorsal neural tube by somitogenesis: a mechanism for coordinating the timing of neural crest emigration. Development 2000, 127:4845-4854.

111. Liem KF Jr, Jessell TM, Briscoe J: Regulation of the neural patterning activity of sonic hedgehog by secreted BMP inhibitors expressed by notochord and somites. Development 2000 127:4855-4866.

112. Capdevila J, Johnson RL: Endogenous and ectopic expression of noggin suggests a conserved mechanism for regulation of BMP function during limb and somite patterning. Dev Biol 1998, 197:205-217.

113. Osorio L, Teillet MA, Catala M: Role of noggin as an upstream signal in the lack of neuronal derivatives found in the avian caudal-most neural crest. Development 2009, 136:1717-1726.

114. Bronner-Fraser M, Fraser SE: Differentiation of the vertebrate neural tube. Curr Opin Cell Biol 1997, 9:885-891.

115. Tanabe $Y$, Roelink H, Jessell TM: Induction of motor neurons by Sonic hedgehog is independent of floor plate differentiation. Curr Biol 1995, 5:651-658.

116. Afonso ND, Catala M: Sonic hedgehog and retinoic acid are not sufficient to induce motoneuron generation in the avian caudal neural tube. Dev Biol 2005, 279:356-367.

117. Teillet M, Watanabe $Y$, Jeffs $P$, Duprez D, Lapointe F, Le Douarin NM: Sonic hedgehog is required for survival of both myogenic and chondrogenic somitic lineages. Development 1998, 125:2019-2030.

118. Mills $C L$, Bellairs R: Mitosis and cell death in the tail of the chick embryo. Anat Embryol 1989, 180:301-308.

119. Olivera-Martinez I, Harada H, Halley PA, Storey KG: Loss of FGF-dependent mesoderm identity and rise of endogenous retinoid signalling determine cessation of body axis elongation. PLOS Biol 2012, 10:e1001415.

120. Olivera-Martinez I, Storey KG: Wnt signals provide a timing mechanism for the FGF-retinoid differentiation switch during vertebrate body axis extension. Development 2007, 134:2125-2135.

121. Miller SA, Briglin A: Apoptosis removes chick embryo tail gut and remnant of the primitive streak. Dev Dyn 1996, 206:212-218.

122. Penaloza C, Lin L, Lockshin RA, Zakeri Z: Cell death in development: shaping the embryo. Histochem Cell Biol 2006, 126:149-158.

123. Di-Poi N, Montoya-Burgos JI, Miller H, Pourquie O, Milinkovitch MC, Duboule D: Changes in Hox genes' structure and function during the evolution of the squamate body plan. Nature 2010, 464:99-103.

124. Gomez C, Ozbudak EM, Wunderlich J, Baumann D, Lewis J, Pourquie O: Control of segment number in vertebrate embryos. Nature 2008, 454:335-339.

125. de Santa BP, Roberts DJ: Tail gut endoderm and gut/genitourinary/tail development: a new tissue-specific role for Hoxa13. Development 2002, 129:551-561.

126. Bellairs R, Osmond M: The Atlas of Chick Development. 3rd edition. Amsterdam, Boston: Elsevier; 2014.

127. Parker TJ, Haswell WA: A Text-book of Zoology. 3rd edition. London: Macmillan and Co., Limited; 1921.

128. Wittkopp PJ, Kalay G: Cis-regulatory elements: molecular mechanisms and evolutionary processes underlying divergence. Nat Rev Genet 2012, 13:59-69.

129. Carroll SB: Evo-devo and an expanding evolutionary synthesis: a genetic theory of morphological evolution. Cell 2008, 134:25-36.

130. Stern DL, Orgogozo V: The loci of evolution: how predictable is genetic evolution? Evolution 2008, 62:2155-2177.
131. Eppig JT, Blake JA, Bult CJ, Kadin JA, Richardson JE: The Mouse Genome Database Group. 2012. The Mouse Genome Database (MGD): comprehensive resource for genetics and genomics of the laboratory mouse. Nucleic Acids Res 2012, 40:D881-D886.

132. Hunt BG, Ometto L, Wurm Y, Shoemaker D, Yi SV, Keller L, Goodisman MA: Relaxed selection is a precursor to the evolution of phenotypic plasticity. Proc Natl Acad Sci U S A 2011, 108:15936-15941.

133. Clarke JA, Zhou Z, Zhang F: Insight into the evolution of avian flight from a new clade of Early Cretaceous ornithurines from China and the morphology of Yixianornis grabaui. J Anat 2006, 208:287-308.

134. Xu X, Tang Z-L, Wang X-L: A therizinosaurid dinosaur with integumentary structures from China. Nature 1999, 399:350-354.

135. Christ B, Wilting J: From somites to vertebral column. Ann Anat 1992 174:23-32.

136. Huang R, Zhi Q, Wilting J, Christ B: The fate of somitocoele cells in avian embryos. Anat Embryol 1994, 190:243-250.

137. Kato N, Aoyama H: Dermomyotomal origin of the ribs as revealed by extirpation and transplantation experiments in chick and quail embryos. Development 1998, 125:3437-3443.

138. Aoyama $H$, Asamoto $K$ : The developmental fate of the rostral/caudal half of a somite for vertebra and rib formation: experimental confirmation of the resegmentation theory using chick-quail chimeras. Mech Dev 2000, 99:71-82.

139. Plummer NW, Spicher K, Malphurs J, Akiyama H, Abramowitz J, Nurnberg B, Birnbaumer L: Development of the mammalian axial skeleton requires signaling through the Galpha(i) subfamily of heterotrimeric G proteins. Proc Natl Acad Sci U S A 2012, 109:21366-21371.

140. Nacke S, Schafer R, de Angelis Habre M, Mundlos S: Mouse mutant "rib-vertebrae" (rv): a defect in somite polarity. Dev Dyn 2000, 219:192-200.

141. White PH: Defective somite patterning in mouse embryos with reduced levels of Tbx6. Development 2003, 130:1681-1690.

142. Kokubu C, Heinzmann U, Kokubu T, Sakai N, Kubota T, Kawai M, Wahl MB, Galceran J, Grosschedl R, Ozono K, Imai K: Skeletal defects in ringelschwanz mutant mice reveal that Lrp6 is required for proper somitogenesis and osteogenesis. Development 2004, 131:5469-5480.

143. Griffith CM, Wiley MJ: Effects of retinoic acid on chick tail bud development. Teratology 1991, 43:217-224.

144. Zwilling E: The development of dominant rumplessness in chick embryos. Genetics 1942, 27:641-656.

145. Noorai RE, Freese NH, Wright LM, Chapman SC, Clark LA: Genome-wide association mapping and identification of candidate genes for the rumpless and ear-tufted traits of the Araucana chicken. PLoS One 2012, 7:e40974.

146. Cavodeassi F, Diez Del Corral R, Campuzano S, Dominguez M: Compartments and organising boundaries in the Drosophila eye: the role of the homeodomain Iroquois proteins. Development 1999, 126:4933-4942.

147. Glavic A, Maris Honore S, Gloria Feijoo C, Bastidas F, Allende ML, Mayor R: Role of BMP signaling and the homeoprotein Iroquois in the specification of the cranial placodal field. Dev Biol 2004, 272:89-103.

148. Heliot C, Desgrange A, Buisson I, Prunskaite-Hyyrylainen R, Shan J, Vainio S, Umbhauer M, Cereghini S: HNF1B controls proximal-intermediate nephron segment identity in vertebrates by regulating Notch signalling components and Irx1/2. Development 2013, 140:873-885.

149. Dunn LC, Landauer W: The genetics of the rumpless fowl with evidence of a case of changing dominance. J Genet 1934, 29:217-243.

150. Dunn LC, Landauer W: Further data on genetic modification of rumplessness in the fowl. J Genet 1936, 33:401-405.

151. Dunn LC: The inheritance of rumplessness in the domestic fowl. J Hered 1925, 16:127-134

152. Marshall CR, Raff EC, Raff RA: Dollo's law and the death and resurrection of genes. Proc Natl Acad Sci U S A 1994, 91:12283-12287.

153. Al-Hashimi N, Lafont AG, Delgado S, Kawasaki K, Sire JY: The enamelin genes in lizard, crocodile, and frog and the pseudogene in the chicken provide new insights on enamelin evolution in tetrapods. Mol Biol Evol 2010, 27:2078-2094. 
154. Sire JY, Delgado SC, Girondot M: Hen's teeth with enamel cap: from dream to impossibility. BMC Evol Biol 2008, 8:246.

155. Hutchinson JR: Biomechanical modeling and sensitivity analysis of bipedal running ability. I. Extant taxa. J Morphol 2004, 262:421-440.

156. Zhou Z, Zhang F: Mesozoic birds of China-a synoptic review. Front Biol (Beijing) 2007, 2:1-14

157. Zhou Z, Zhang F: Jeholornis compared to Archaeopteryx, with a new understanding of the earliest avian evolution. Naturwissenschaften 2003, 90:220-225

doi:10.1186/2041-9139-5-25

Cite this article as: Rashid et al:: From dinosaurs to birds: a tail of evolution. EvoDevo 2014 5:25

\section{Submit your next manuscript to BioMed Central and take full advantage of:}

- Convenient online submission

- Thorough peer review

- No space constraints or color figure charges

- Immediate publication on acceptance

- Inclusion in PubMed, CAS, Scopus and Google Scholar

- Research which is freely available for redistribution 